\title{
LOS RETOS DE LA CIUDAD COMPACTA DESDE LA PERSPECTIVA DE LOS CASCOS HISTÓRICOS CON FUERTE ACTIVIDAD TURÍSTICA. EL CASO DE TOLEDO
}

\author{
Eloy Solís \\ Universidad de Castilla-La Mancha \\ eloy.solis@uclm.es \\ ORCID iD: https://orcid.org/0000-0003-2950-730X \\ Luis Alfonso Escudero \\ Universidad de Castilla-La Mancha \\ Luisalfonso.escudero@uclm.es \\ ORCID iD: https://orcid.org/0000-0002-7954-4064 \\ Borja Ruiz-Apilánez \\ Universidad de Castilla-La Mancha \\ borja.ruizapilanez@uclm.es \\ ORCID iD: https://orcid.org/0000-0002-2857-3965
}

Recibido: 22-07-2019 Aceptado: 28-01-2020.

CÓMO CITAR ESTE ARTícULO/CITATION: Solís, Eloy; Escudero, Luis Alfonso y Ruiz-Apilánez, Borja (2020). Los retos de la ciudad compacta desde la perspectiva de los cascos históricos con fuerte actividad turística. El caso de Toledo. Estudios Geográficos, 81 (288), e035. https://doi.org/10.3989/estgeogr.202050.030

RESUMEN: Los cascos históricos representan la forma tradicional sobre la que se ha construido el paradigma de la ciudad compacta, densa y diversa, y, de forma más amplia, el modelo de ciudad sostenible. No obstante, se plantea en qué medida los problemas y retos a los que se enfrentan estos espacios garantizan un desarrollo urbano sostenible. Al mismo tiempo, ¿cuáles son los retos y cómo avanzar hacia el desarrollo sostenible en formas urbanas compactas como son los cascos históricos con fuerte actividad turística? Responder a estas preguntas es el objetivo primordial de la investigación. Para ello, empleamos una metodología hipotético-deductiva y recurrimos a la revisión literaria y a la utilización de datos de diferentes fuentes, incluyendo el trabajo de campo y la observación directa. En los resultados, se realiza la revisión de los marcos y planteamientos principales en los que se ha movido la intervención en cascos históricos en España y se señalan las dinámicas más importantes en curso, contrastándolas con el estudio de caso de Toledo. Se destacan dos conclusiones: uno, el desajuste entre el carácter sostenible del modelo espacial y la emergencia de un modelo insostenible en el plano funcional y socioeconómico, y dos, la necesidad de revertir dicho desfase mediante una mayor coordinación entre administraciones y políticas sectoriales y una mejor regulación y control. Esta práctica contribuye a la comprensión de los cascos históricos en el presente.

PALABRAS CLAVE: Centros históricos; cascos antiguos; sostenibilidad; turistificación; museificación; gentrificación.

\section{THE CHALLENGES OF THE COMPACT CITY FROM THE PERSPECTIVE OF THE HISTORIC CENTRES WITH OUTSTANDING TOURIST ACTIVITY. THE CASE OF TOLEDO}

ABSTRACT: Historical centres represent the traditional form on which the paradigm of the compact, dense and diverse city has been built and, more broadly, the sustainable city model. However, the extent to which the current problems and challenges faced by these spaces guarantee sustainable urban development is questioned. At the same time, what are the challenges and how can we move towards sustainable development in compact urban forms such as historic centres with strong tourist activity? Answering these questions is the primary objective of the research. For this, we employ a hypothetical-deductive methodology and resort to literary revision and the use of data from different sources, including field work and direct observation. In the results, we review the main frameworks and approaches in which the intervention in historic centres in Spain has been carried out and point out the most important dynamics in progress, contrasting them with the Toledo case study. Two conclusions stand out: the mismatch between the sustainable nature of the spatial model and the emergence of an unsustainable model in the functional and socioeconomic plane and the need to reverse this mismatch through greater coordination between administrations and sectoral policies and better regulation and control. We consider that the main practical application of this research is to contribute to the understanding of historic centres in the present.

KEYWORDS: Historical centres; old towns; sustainability; tourism; museification; gentrification.

Copyright: ( 2020 CSIC. Este es un artículo de acceso abierto distribuido bajo los términos de la licencia de uso y distribución Creative Commons Reconocimiento 4.0 Internacional (CC BY 4.0). 
La visión de la ciudad compacta ha estado dominada por el modelo del núcleo densamente desarrollado de muchas ciudades históricas europeas. Son un gran atractivo no sólo para arquitectos, planificadores y diseñadores urbanos, sino también para innumerables turistas que acuden en masa. Son vistos, a menudo por los que vienen de fuera, como lugares ideales para vivir y experimentar la vitalidad y variedad de la vida urbana.

(Jenks, Burton y Williams, 1996, p. 5)

\section{INTRODUCCIÓN}

Empleamos la noción de casco antiguo, casco histórico o centro histórico para referirnos en sentido amplio a la ciudad producida antes de la industrialización, es decir, a la ciudad histórica o preindustrial (Capel, 1975; Estébanez, 1989). Este hecho denota un espacio que es punto de origen y confluencia identificable en la estructura urbana, y hace referencia a un lugar cuyo espacio y materialidad están determinados por su antigüedad y simbolismo cultural, político y económico asociado (Ordóñez, 2017). Capel (2007) señala que "los centros históricos son necesarios, y su atractivo muestra que cumplen una función simbólica muy importante (...) A través de él nos enraizamos con la historia, tenemos o adquirimos el sentido de la continuidad» (s. pág.). Con el proceso de industrialización y la afirmación del capitalismo, los cascos históricos, en función de la trayectoria de la ciudad y el territorio en el que se insertan, mantienen, pierden, o comparten con otras partes de la ciudad el carácter de centralidad funcional (Troitiño, 1991, Martínez, 2001; Solís, Mohíno y Ureña, 2018). Esto supone que el casco histórico puede o no coincidir con el centro urbano ${ }^{1}$. A ello, se superpone la noción de conjunto histórico patrimonial, el cual engloba la totalidad o parte del casco histórico que queda sujeto a una protección legal por su carácter de Bien de Interés Cultural ${ }^{2}$. El potencial de estos conjuntos históricos radica en el entrelazamiento de la componente material - singularidad natural como consecuencia de las características de los emplazamientos, tramas urbanas de base medieval que confieren especial personalidad al trazado, presencia de edificios monumentales, yuxtaposición de espacios residenciales con características diferentes, etc.-, la componente inmaterial - fiestas, eventos lúdicos, oferta cultural, etc. - el paisaje y el sentido de lugar resultante (De la Calle y García, 1998).

Los cascos históricos son la materialización más acabada de la forma urbana tradicional y han intere- sado a múltiples disciplinas científicas, entre ellas la Geografía, la Sociología, la Economía, etc. Desde mediados del siglo XX los cascos históricos se han interpretado desde dos perspectivas (Álvarez y Roch, 1980; Bonet y Gavira, 1987; Campesino, 1989; Troitiño, 1991, 2003a; Álvarez, 1993; 1999; 2001, 2011; González-Varas, 2006, 2016; Solís, Mohíno y Ureña, 2018). La primera, los entiende como «unidad de actuación». Aquí se establece una diferenciación entre (a) el casco histórico como unidad espacial de acción de políticas e instrumentos para la protección, conservación, recuperación, rehabilitación y revitalización, y (b) como unidad espacial de investigación para generar el conocimiento sobre el que basar y evaluar lo anterior. La segunda perspectiva destaca la atención en el casco histórico como "bien cultural». En este caso se realiza una distinción entre (a) el casco histórico como bien vinculado al derecho de la colectividad a su memoria histórica o al disfrute del legado del pasado y herencia cultural para su futuro, y (b) como generador de riqueza ligada al turismo, es decir, como espacio-mercancía (Fig. 1).

En el seno de estas interpretaciones, este artículo plantea reflexionar sobre la siguiente contradicción: ¿en qué medida el casco histórico se promueve como paradigma de la ciudad compacta y sostenible $y$, a su vez, se tiende a construir un espacio orientado al consumo (turístico); es decir, un espacio preparado para la expansión del capitalismo -circulación de mercancías, personas, servicios y capitales-? El estudio plantea la siguiente hipótesis: mientras que los cascos históricos han sido ejemplo para impulsar y guiar el crecimiento urbano sostenible (Jenks, Burton y Williams, 1996; Mega, 1996; De Moura, 2001; Rodwell, 2010; Van Oers y Pereira Roders, 2012; Fezzai, Mazouz y Ahriz, 2015), al mismo tiempo exhiben dinámicas socioeconómicas y funcionales que se alejan del paradigma de la sostenibilidad. Los cascos históricos van perdiendo población residente en favor de una mayor presencia de turistas (museificación), se especializan funcionalmente de la mano del turismo (turistificación) y pierden diversidad social en favor de población con mayor capacidad de renta (gentrificación).

Los esfuerzos dirigidos a revitalizar los centros históricos, el favorecimiento del desarrollo turístico, así como los comercios y la prestación de servicios e infraestructuras específicos para los visitantes han llevado a la gentrificación, la privatización de los espacios públicos y nuevas formas de vigilancia (Dürr y Jaffe, 2012). Progresivamente, la vida en estos espa- 
FIGURA 1

INTERPRETACIONES DEL CASCO HISTÓRICO

\begin{tabular}{|c|c|c|}
\hline & $\begin{array}{c}\text { Del casco histórico como } \\
\text { espacio aislado a su encaje en } \\
\text { el contexto urbano y } \\
\text { territorial }\end{array}$ & $\begin{array}{l}\text { Del casco histórico como } \\
\text { colección de monumentos } \\
\text { aislados a la dimensión } \\
\text { patrimonial del conjunto } \\
\text { urbano -integrando aspectos } \\
\text { espaciales, ambientales, } \\
\text { económicas, sociales, } \\
\text { culturales, ...- }\end{array}$ \\
\hline & $\begin{array}{l}\text { El casco histórico como } \\
\text { «unidad de actuación» }\end{array}$ & $\begin{array}{l}\text { El casco histórico como «bien } \\
\text { cultural» }\end{array}$ \\
\hline $\begin{array}{l}\text { Marco legislativo y regulador } \\
\text { de las políticas y la } \\
\text { planificación } \\
\text { (enfoque normativo) }\end{array}$ & $\begin{array}{c}\text { Políticas sectoriales y régimen } \\
\text { urbanístico (planes especiales } \\
\text { de protección y catálogos de } \\
\text { protección - monumentos, } \\
\text { residencial, espacios y paisaje } \\
\text { urbano, etc.) }\end{array}$ & $\begin{array}{c}\text { Espacio para la fruición } \\
\text { colectiva } \\
\text { (valorización del legado } \\
\text { histórico-cultural) }\end{array}$ \\
\hline $\begin{array}{l}\text { Marco de la investigación } \\
\text { urbana } \\
\text { (enfoque prescriptivo) }\end{array}$ & $\begin{array}{c}\text { Estudio de las cualidades } \\
\text { físicas, funcionales y sociales } \\
\text { del espacio urbano y } \\
\text { evaluación de las políticas y la } \\
\text { planificación }\end{array}$ & $\begin{array}{c}\text { Espacio-mercancía } \\
\text { (mercantilización del } \\
\text { patrimonio y del espacio que lo } \\
\text { acoge) }\end{array}$ \\
\hline
\end{tabular}

Fuente: Elaboración propia.

cios deja de estar sustentada por la cotidianeidad de acciones y movimiento de residentes y pasa a estarlo por los ritmos de los turistas. Es evidente que los residentes tradicionales ya no son los únicos que viven y usan estas áreas (Scarnato, 2006). Ya a finales del siglo pasado, Troitiño (1999) señalaba la necesidad de contrarrestar en los cascos históricos los procesos de terciarización, refiriéndose a la excesiva especialización turística; de desertización, señalando con ello el proceso de despoblación derivado; y de gentrificación. Sin embargo, transcurridas dos décadas del actual siglo, estos procesos no se han compensado, en el caso del despoblamiento, o se han agravado, en lo relativo a la turistificación y la elitización. Por eso, en la actualidad se debe evaluar el nivel de terciarización, gentrificación y despoblamiento de los centros históricos (Pulido y Ruiz, 2017), tal y como hace este estudio para el caso de Toledo.

Conforme a este hilo argumental y partiendo de la convicción de que la transformación urbana es siempre un proceso altamente político (Castells, 2002; Lefebvre, 2017), el artículo se organiza de la siguiente manera. En primer lugar, se delimitan la zona de estudio y se detallan materiales y métodos empleados (apartado 2). A continuación, se revisan las principales vías de intervención que han afectado a los cascos históricos desde la segunda mitad del siglo XX en España (apartado 3). Después, señalamos las dinámi- cas fundamentales en curso en las que están envueltos los cascos históricos, utilizando como Toledo como caso de estudio (apartado 4). Por último, aportamos algunas reflexiones y posibles líneas de investigación futuras en relación a los retos de los cascos históricos con fuerte atracción turística (apartado 5).

\section{ZONA DE ESTUDIO, MATERIALES Y MÉTODOS}

El presente artículo se estructura a partir de un estudio de caso, la ciudad de Toledo. Esta aproximación se considera apropiada para una investigación ya que permite definir el tema más ampliamente al considerar los problemas contextuales en el caso y confiar en múltiples fuentes de evidencia (Yin, 2003). El casco histórico de Toledo -en adelante, CHT-, fue declarado Conjunto Histórico Artístico en $1940^{3}$ y Ciudad Patrimonio de la Humanidad por la UNESCO en 1986. El conjunto protegido tiene una superficie aproximada de $260 \mathrm{Ha}^{4}$. Su carácter monumental está ligado a que en poco más de $100 \mathrm{Ha}$ que ocupa su recinto amurallado se suman 103 edificios con valor monumental, 281 edificios que el Plan Especial del $\mathrm{CHT}$ identifica con valor patrimonial y 440 con aspectos o elementos de interés patrimonial (Busquets, 2000) (Fig. 2). Un estudio elaborado en 1998 recogía la llegada de más de 1 millón y medio al año de vi- 
sitantes - turistas y excursionistas - (Troitiño et al., 1998). La cifra real hoy está más próxima a los 3 millones (Escudero, 2018a). Según datos del INE, el número de viajeros en 2018 fue de 600.545 (391.859 residentes en España y 208.686 en el extranjero), mientras que las pernoctaciones alcanzaron la cifra de 924.246 (610.884 residentes en España y 313.362 en el extranjero).

En este artículo se utiliza un método hipotéticodeductivo. Planteada la hipótesis de trabajo, a partir de principios generales sobres los cascos históricos

FIGURA 2

DELIMITACIÓN DEL CASCO/CIUDAD HISTÓRICA, RECINTO AMURALLADO Y DEL CONJUNTO HISTÓRICO DE TOLEDO SOBRE FOTOGRAFÍA AÉREA Y VISTA DEL CASCO HISTÓRICO DE TOLEDO

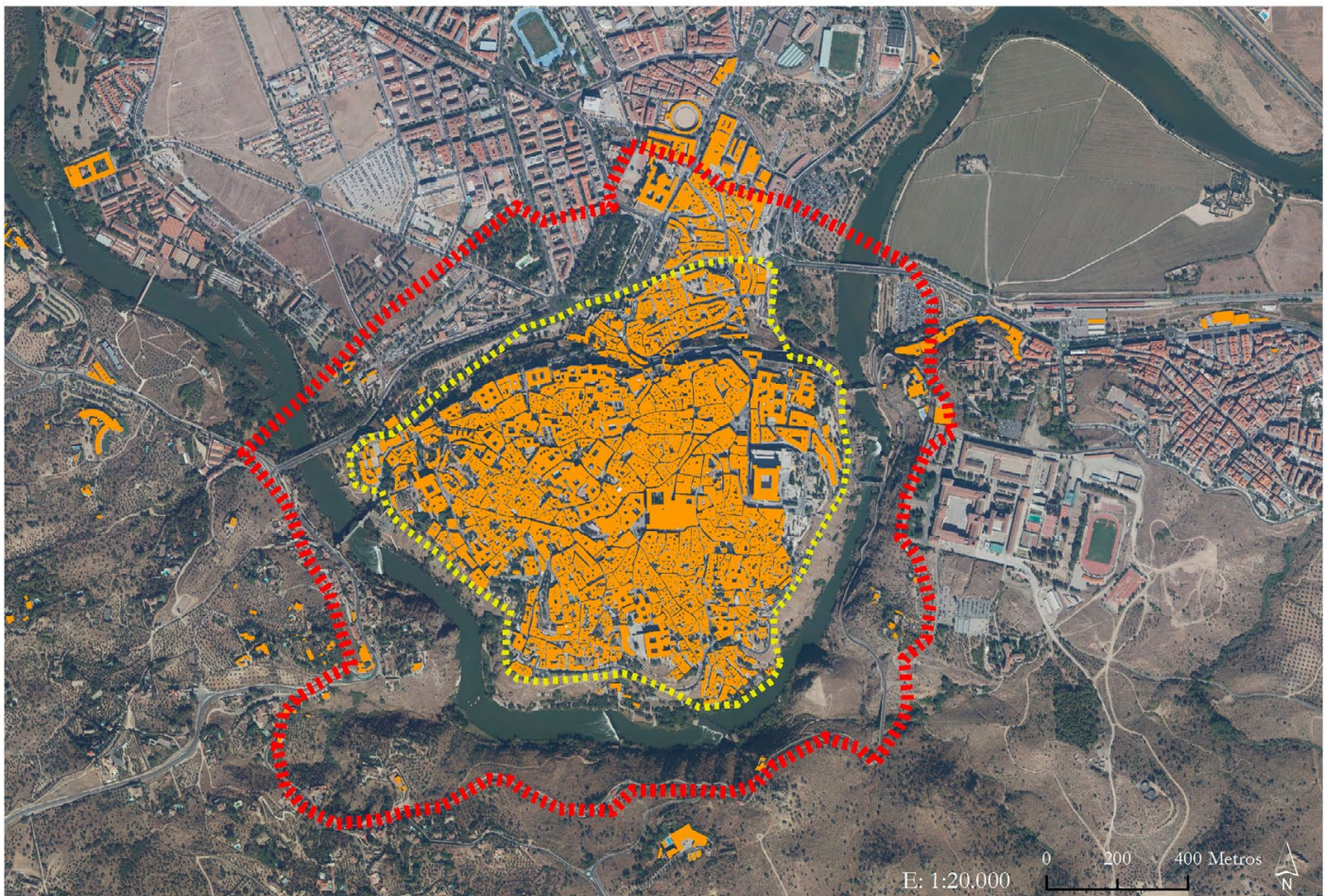

Espacio edificado antes de 1900 Límite del recinto amurallado IIII Límites del Conjunto Histórico de Toledo

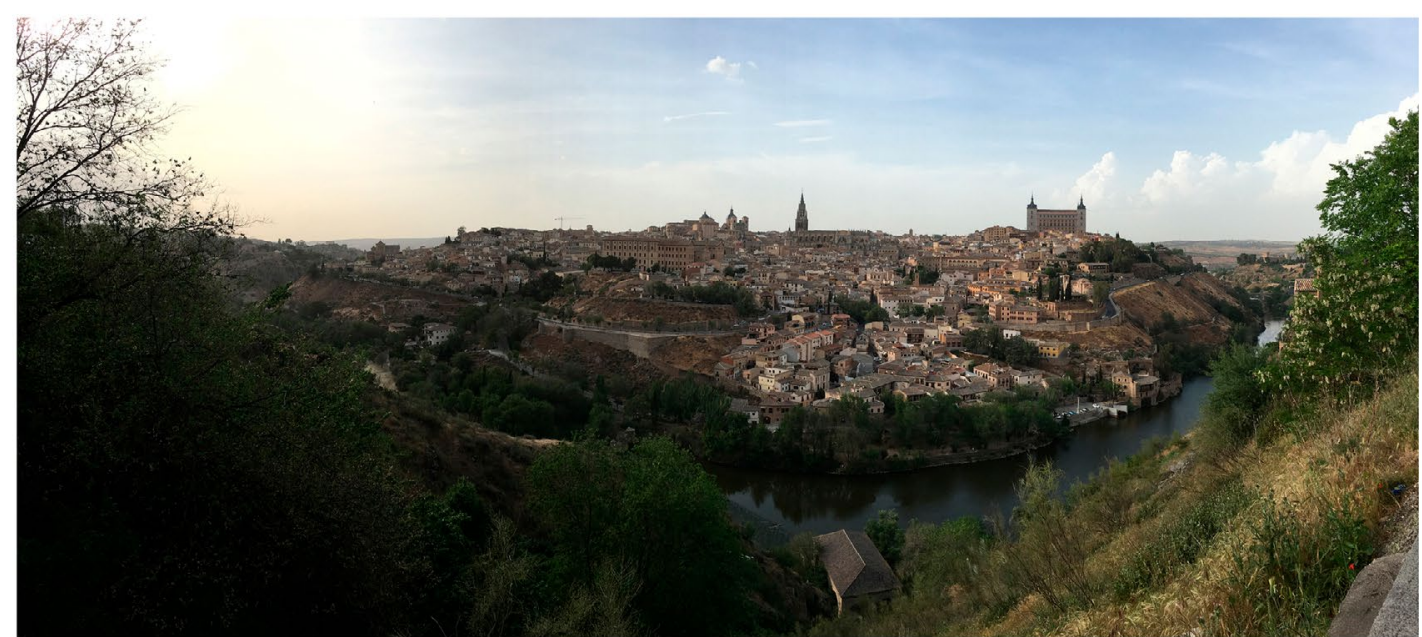

Fuente: elaboración propia y PNOA. Fotografía de Escudero, 24/4/2017. 
se recurre a la deducción para alcanzar conclusiones particulares en el caso de Toledo. El espacio geográfico es multidimensional y en constante cambio, así sucede con los cascos históricos. Por estas razones, y para alcanzar los objetivos propuestos, se opta por un acercamiento holístico al tema investigado. Como consecuencia de tratar múltiples realidades de los cascos históricos, se utilizan diferentes fuentes.

Las estrategias de investigación del artículo combinan formas teóricas y empíricas. De este modo, tras una revisión de literatura seleccionada, fundamental para vertebrar el marco teórico del artículo, se emplean diferentes fuentes de datos de población, turismo, usos de suelo, vivienda, etc. Estos se tratan de forma estadística, gráfica y cartográfica. Para su obtención se ha recurrido a estudios parciales anteriores, por ejemplo, sobre vivienda (Camarena, 2018) o sobre el desarrollo de la actividad turística (Escudero, 2018a), así como a documentos de planeamiento como el Plan Especial del Centro Histórico de Toledo. Al mismo tiempo, se ha acudido a dos fuentes de información demográfica claves en España, el censo de población y el padrón municipal de habitantes (Reher y Valero, 2005). También a los datos disponibles en el catastro inmobiliario, de gran utilidad en estudios de Geografía Urbana (Pillet, 2008). Como trabajo empírico directo de los autores se utiliza el trabajo de campo realizado en 2014 para obtener la distribución de las actividades económicas en el casco histórico. Por último, este artículo no sería posible sin la observación directa de la zona de estudio por parte de los autores, entendiendo que el método de observación se basa en la capacidad del observador para interpretar lo que está sucediendo y por qué (Kitchin y Tate, 2000).

Finalmente, hay que señalar que la metodología descrita ha permitido incluir algunas ideas de tipo propositivo, y como tales subjetivas y abiertas a la discusión, sobre todo en las conclusiones.

\section{LOS CASCOS HISTÓRICOS DESDE LA SEGUNDA MITAD DEL SIGLO XX: VÍAS DE INTERVENCIÓN}

A lo largo del siglo XX y sobre todo desde los años 50 , los cascos históricos han sido foco de atención para su preservación, renovación, restauración y recuperación, al tiempo que se adoptaban estrategias de revitalización urbana económicas y sociales. Este hecho ha supuesto un proceso de reorganización socioeconómica y física interna. Si bien es cierto que ello supone admitir que no existe una única vía de intervención en los cascos históricos (Troitiño, 1991; 2003b; González-Varas, 2016), no hay evidencias que indiquen que las actuaciones emprendidas tengan como finalidad la sostenibilidad. Al contrario, parece que los cascos históricos se han ido preparando como lugares para la acumulación capitalista (Álvarez y Roch, 1980; Álvarez, 1993, 1999; 2001; Sorando y Ardura, 2016, Hernández, 2016, Hernández, 2018). A continuación, hacemos un breve recorrido que nos ayuda a contextualizar esta interpretación.

EI VIII CIAM - The Heart of the City: Towards the Humanization of Urban Life celebrado en Hoddesdon (Inglaterra) en $1951^{5}$ propuso el corazón como metáfora de la creación de centros de vida social, lugares con significado e historia, espacios con forma y dimensión presumiblemente adecuada, complejidad, diseño de la ciudad como mezcla vertical de funciones, la escala humana, etc. (Ramírez, 1997; Zuccaro, 2013). Aunque esta imagen es susceptible de aplicarse a diferentes espacios de la ciudad ${ }^{6}$, la destrucción provocada por la II Guerra Mundial y la expansión indefinida de la periferia, motivaron la vuelta a la ciudad histórica (Frampton y Mumford, 2000; Mumford, 2007) ${ }^{7}$. Las cualidades físicas, sociales y funcionales de las áreas centrales de las ciudades, muchas veces coincidiendo con los cascos históricos, se preparaban como campo de trabajo para (re)formular criterios y principios racionales de diseño urbano que permitieran, por un lado, intervenir en dichos espacios, y por otro, crear un arquetipo de urbe que contraponer a la ciudad difusa.

En el tercer cuarto del siglo se publican diferentes declaraciones internacionales que señalan la necesidad de proteger los cascos históricos. Especialmente, sus espacios urbanos y monumentos principales. Así, en 1964 aparece la Carta de Venecia o Carta Internacional para la Conservación y Restauración de Monumentos y Sitios como resultado del II Congreso Internacional de Arquitectos y Técnicos de Monumentos Históricos, celebrado en Venecia ese mismo año. Unos años después se publica la Declaración de Ámsterdam, en 1975, que propone la conservación del patrimonio arquitectónico europeo, promulgada por el Consejo de Europa. Cabe destacar que se propone que la conservación y reutilización «estuviera guiada por un espíritu social, defendiendo que los habitantes originarios permanecieran en los cascos históricos renovados» (García, 2004, p. 10). Se consolida así la necesidad de salvar los centros históricos (Hall, 1969).

No obstante, se considera que es la restauración emprendida en el centro histórico de la ciudad de Bo- 
lonia, iniciada a finales de los 1960, la que supuso un ejemplo de referencia y la que dio lugar a actuaciones similares a partir de entonces en los cascos históricos de las ciudades europeas. Su modelo de recuperación y rehabilitación de edificios y espacios públicos será ampliamente imitado posteriormente (Marín, Guevara y Navarro-Jurado, 2017). En Bolonia no se trató solo de preservar el patrimonio arquitectónico y los monumentos históricos, sino que también se pretendía dinamizar su estructura urbana. El objetivo era potenciar las funciones universitarias, culturales, turísticas, representativas, artesanales y, sobre todo, residenciales (Cervellati y Scannavini, 1976). Ordeig (2004) señala que «el caso de Bolonia representa, en definitiva, el convencimiento de que el urbanismo no puede cerrar los ojos a una realidad social a la que debe servir y que es mucho más importante que los medios técnicos y que lo que significa el capital. Se puede sostener que representa el punto de partida de la masiva difusión de los nuevos foros sobre los centros históricos que recorrió toda Europa en la década de los años setenta» (p. 171). En las ciudades europeas se van realizando diferentes planeamientos para preservar y conservar sus cascos históricos (Slater, 1984) y lograr su revitalización (Tiesdell y Heath, 1996; Troitiño, 2003b).

A grandes rasgos, se acabaron promovieron dos grandes enfoques en la intervención de los cascos históricos: (a) el urbanismo racionalista o de la renovación urbana y (b) el urbanismo cultural o de la recuperación urbana.

El urbanismo racionalista retenía la base funcionalista de la preguerra y entendía que las áreas centrales de la ciudad, debido a sus aptitudes - accesibilidad, imagen, prestigio, etc.-, debían ser arrasadas para alojar las actividades con mayor capacidad de pujar por el espacio - comercio especializado, finanzas, ocio lucrativo, etc. (Ribas, 1981; Troitiño, 1991, Álvarez, 1993; Valenzuela, 2000) ${ }^{8}$ - . Este proceso de intervención es conocido como renovación urbana (urban renewal) y se apoyó en una inversión selectiva que buscaba la renovación de la edificación -en muchos casos a través de políticas urbanas que acabaron favoreciendo su gentrificación (Bailey y Robertson, 1997)—, equipamientos e infraestructuras de la ciudad, necesaria a consecuencia de su envejecimiento o, la mayor parte de las veces, para adaptarla a nuevos usos más rentables y lucrativos. Ello derivó en el fenómeno de la gentrificación, evidenciado en la elitización y especialización de ciertas partes de la ciudad (Glass, 1964; Sorando y Ardura, 2016; Hernández, 2016). Es claro que no todas las ciudades son afectadas por este pro- ceso, ni en la misma intensidad. Hay núcleos urbanos y sectores internos de los cascos históricos que quedan marginados temporalmente - por ejemplo, los narcopisos en Ciutat Vella de Barcelona-. En el caso de España, Pol (1993) señala que en los años 60 y 70 del siglo XX las ciudades más dinámicas se sometieron a un proceso de destrucción y sustitución de los centros, con unos efectos sociales y unas implicaciones arquitectónicas y urbanas especialmente perversas, al romper los tejidos históricos, implantando nuevas edificaciones, casi siembre de gran volumetría, basadas en banales aplicaciones de los esquemas de la ya codificada arquitectura funcional. Si bien es cierto que la renovación física y funcional es necesaria, ésta carecía de control y generaba especulación. La situación era justo la contraria a la demandada por Lefebvre (2017) y la realidad urbana no estaba destinada a los residentes y trabajadores de los cascos antiguos, sino a los especuladores, a los promotores capitalistas, etc.

El urbanismo cultural y la recuperación urbana son dos términos propuestos por Culot (1988) para referirse a la idea de protección, conservación y recuperación de la ciudad histórica heredada y dar respuesta a los problemas y necesidades de la población que habita en los cascos históricos frente a visiones meramente conservacionistas y especulativas (en Pol, 1993). Este enfoque se entrelazó con una nueva lectura e interpretación del patrimonio. Como señala GonzálezVaras (2006), la reformulación del concepto de bien cultural a mediados de los 1950 derivó en una renovación profunda en el ámbito de la conservación y la restauración, al propiciar el paso de la tutela y protección del monumento hacia la de los cascos históricos, y desde allí hasta la del territorio culturalmente significativo. A partir de los 70 del siglo $\mathrm{XX}$, los cascos antiguos comenzaron a entenderse como bienes culturales y económicos que precisan ser protegidos por los efectos negativos de las especulaciones, y en los que había y hay que adoptar criterios de intervención que apuesten en el plano funcional por el desarrollo de actividades que contribuyeran al mantenimiento del aspecto y la estructura social y económica tradicional de dichos espacios, evitando la expulsión de las capas de población originales (Zárate y Vázquez, 1988; Valenzuela, 1988; Troitiño, 1991; Zárate, 2006; GonzálezVaras, 2016) ${ }^{9}$. Como señalan Campesino (1999), Troitiño (2003b) o Gomá (2018), tanto los marcos legislativos, como los instrumentos de planificación y gestión, o las inversiones públicas han fracasado en este propósito. En parte por no considerar de forma adecuada las dimensiones ambientales, sociales y funcionales (Troitiño y Troitiño, 2010). 
El urbanismo racionalista, así como el de la recuperación urbana, vio irrumpir a partir de 1970 el debate de los límites del crecimiento y el equilibrio ambiental. Resultado de ello, fue la incorporación de la sostenibilidad a dicho enfoque a partir de 1990. La sostenibilidad entendida en un sentido amplio da entrada a diferentes aspectos a considerar, tales como la habitabilidad y condiciones del edificio, la gestión del tráfico y aparcamiento en relación al incremento de la contaminación y el deterioro del patrimonio y la calidad de vida, la capacidad de carga física y socioeconómica, las implicaciones en el mobiliario urbano, tendido eléctrico, la señalética, los aspectos compositivos externos de edificios, etc. (Troitiño et al., 1998; Busquets, 2000; García, 2000; González, 2006).

Estos enfoques se encuentran en el último cuarto del siglo pasado con un nuevo marco político-económico caracterizado por dos grandes procesos: la globalización y el reescalamiento del poder político y económico de los Estados. La globalización supone un cambio económico y cultural en el que el patrimonio urbano - conectado a elementos materiales e inmateriales - puede ser aprovechado como un recurso turístico (De la Calle y García, 1998; Pulido, Calle y Velasco, 2013). Este hecho abre la puerta a un proceso de mercantilización del espacio urbano patrimonial y del conjunto de infraestructuras que permite la accesibilidad, estancia y alojamiento de turistas. Por otro lado, el reescalamiento supone una mayor capacidad decisional y económica a nivel regional y local, a la vez que se favorece la integración en espacios supranacionales, como la de España en la Unión Europea y en nuevos acuerdos internacionales. Se define con ello un escenario de poder que, bajo el posicionamiento neoliberal imperante, legisla y planifica con incidencia en la producción y remodelación del espacio al servicio del marketing urbano y del consumo (Carrión, 2012). Estos dos procesos definen el marco estructural en el que se desenvuelve la intervención y dinámicas en las ciudades en general $y$, en particular, en los cascos históricos. Considerando este nuevo contexto, en el siguiente apartado señalamos algunas tendencias en curso para los cascos históricos, contrastadas para el caso de Toledo.

\section{DiNÁMICAS EN LOS CASCOS HISTÓRICOS CON FUERTE ATRACTIVO TURÍSTICO: EL CASO DE TOLEDO}

No todos los cascos históricos son iguales ni todos se enfrentan a las mismas dinámicas (Zárate y Vázquez, 1988; Valenzuela, 1988; Troitiño, 1991, 1992,
2003; Martínez, 2001; Ferrer, 2003; Tomé, 2007; Santamaría, 2013), aunque pueden observarse un conjunto de tendencias similares para aquellos que poseen una centralidad funcional y un destacado atractivo turístico. A continuación, se presentan las principales dinámicas de los cascos históricos con fuerte atractivo turístico, acompañando evidencias en el caso de Toledo.

\subsection{Funciones actuales que mantienen el patrimonio monumental}

Reconociendo la importancia de valorar y mantener el patrimonio, ha primado una política de protección y rehabilitación de edificios singulares o conjuntos arquitectónicos de carácter monumental ligados a la función administrativa y sociocultural conectada al turismo y, en menor medida, a otras funciones como la universitaria u otras de tipo sociocultural vinculadas a los residentes (Campesino, 1989; Vázquez, 2000; Aparicio, Serrano y León, 2018). En el caso de Toledo, la condición de capital regional y provincial ha sido un factor palanca de renovación, recuperación urbana y crecimiento (Campos, 1999; 2002; Aparicio y Martínez, 2015). El patrimonio monumental e histórico ha sido aprovechado por el poder político para localizar diferentes instituciones. En paralelo a esta situación, el poder económico, por ejemplo, a través de sedes bancarias ha ido ocupando edificios históricos o parte de estos. A partir de la pujanza del turismo se han habilitado y creado espacios culturales al tiempo que se han restaurado edificios religiosos. En la Figura 3 se representan a fecha actual las funciones administrativas, culturales, universitarias y de tipo religioso junto con la localización de los Bienes de Interés Cultural (BIC) del casco histórico de Toledo (CHT). Estos usos representan el 35,9\% del espacio urbano parcelado y, la inmensa mayoría se encuentran en edificios protegidos, ya sea por su condición de BIC o por estar incluidos en el Catálogo de Bienes y Espacios Protegidos del Ayuntamiento de Toledo. La distribución espacial de estos inmuebles otorga al Casco Histórico de Toledo diversidad de funciones y dinamismo.

\subsection{El caserío popular: ¿un patrimonio al servicio de la especulación?}

El caserío popular ha tenido una trayectoria compleja, en la que se diferencian tres grandes tipos de 


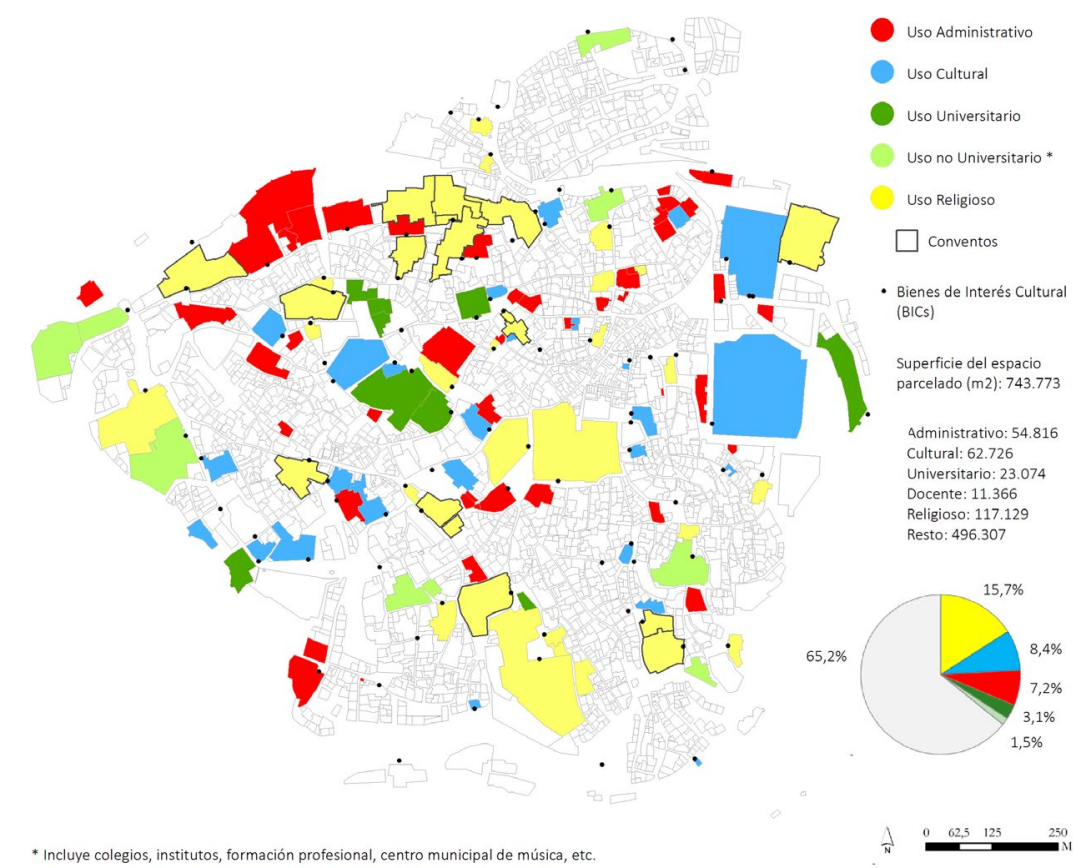

Fuente: Catastro y elaboración propia.

actuación en viviendas y edificios: derribo y obra nueva, rehabilitación y adecuación y marginación física. A pesar de que en el Congreso de Bérgamo de $1971^{10}$ se destacó el valor patrimonial del caserío popular y el papel que deben jugar los cascos históricos en la resolución del problema de la vivienda, y más concretamente el de la vivienda popular (Álvarez, 1993), como ha puesto de manifiesto Xosé Allegue, arquitecto de Santiago de Compostela y participante en el Foro sobre Habitabilidad y Rehabilitación en las Zonas Monumentales celebrado en Cuenca 2016, las políticas públicas de vivienda son todavía un reto pendiente de los cascos históricos ${ }^{11}$. Allegue llama la atención sobre el fenómeno de la "rehabilitación especulativa subvencionada» para referirse a la recuperación física orientada a incrementar el valor del alquiler - uso turístico de las viviendas - o el precio de venta de la vivienda o inmueble, sin que ello redunde en la presencia de una buena mezcla social. Si a esto se suma la falta de movilización de la vivienda vacía o el escaso fomento de la vivienda pública en estos ámbitos, el resultado tiende a reproducir un modelo de gentrificación (Álvarez, 1999; Sorando y Ardura, 2016). Sencillamente, se produce una sustitución del colectivo residente tradicional por pobla- ción con capacidad adquisitiva más elevada, ya sea de forma permanente o temporal. Toledo se inserta así en una estrategia de desarrollo urbano global que se está incrementando en la actualidad (Smith, 2002). Según Sorando y Ardura (2016), «la gentrificación es un signo local de las estrategias más amplias del neoliberalismo global» (p. 23).

Un reciente estudio sobre el fenómeno de la vivienda con uso turístico en el CHT señala que, en base a los datos extraídos de la plataforma Airbnb a fecha de 1 de junio de 2018, tiene 441 viviendas completas disponibles para acoger turistas y 79 habitaciones privadas en viviendas particulares. Esta oferta ofrece una capacidad de hospedaje de 2.144 personas, lo que supone un $48,36 \%$ sobre la disponibilidad total de hospedaje en Toledo, teniendo en cuenta que existen 4.433 plazas hoteleras estimadas por el INE para abril de 2018 (Camarena, 2018). Es decir, hay casi la mitad de las plazas en viviendas de uso turístico que en ofertas de alojamiento regladas.

El CHT no ha contado hasta finales de los años 1980 con una política dirigida a la rehabilitación residencial (Zárate, 1991). Desde entonces cabe destacar dos momentos. El primero, previo a la aprobación del Plan 
Especial del Centro Histórico de Toledo (PECHT), con la puesta en marcha de en los años 1980 del Toledo a Plena Luz, dentro del programa Castilla-La Mancha a Plena Luz ${ }^{12}$. El segundo, tras la aprobación del PECHT en 1997, articulado en dos periodos, desde 1998 a 2001 a través de las actuaciones conjuntas de la Consejería de Obras Públicas y el Ayuntamiento ${ }^{13}$, y desde 2001 hasta el momento actual con las actuaciones gestionadas por el Consorcio de Toledo -ente gestor y administrativo del Real Patronato de Toledo-. Según el estudio realizado por el Consorcio en 2018, entre 2001 y 2018 se ha subvencionado la rehabilitación (entre obras menores y mayores) de más de 2.700 viviendas en el CHT. En la Figura 4 se ha representado las intervenciones en materia de rehabilitación efectuada en este tiempo por el Consorcio y los $21 \mathrm{sec}-$ tores de actuaciones residencial que planteaba el Plan Especial y se muestra, a modo de ejemplo, una.

Recientemente, desde el Ayuntamiento de Toledo y la Universidad de Castilla-La Mancha (UCLM) se ha elaborado el Estudio de demanda de vivienda en el municipio de Toledo (2017), el Diagnóstico de vivienda y rehabilitación de Toledo (2018) y el Informe sobre la vivienda en Toledo (2018), y cabe señalar al respecto dos hechos. El primero, la información que se recaba de tipo cualitativa - basada en encuestas a

FIGURA 4

LOCALIZACIÓN DE INTERVENCIONES EFECTUADAS POR EL CONSORCIO DE TOLEDO: REHABILITACIÓN DE VIVIENDAS Y EDIFICIOS Y REHABILITACIÓN MONUMENTAL DENTRO DEL RECINTO AMURALLADO DE TOLEDO (2001-2018) Y UN EJEMPLO

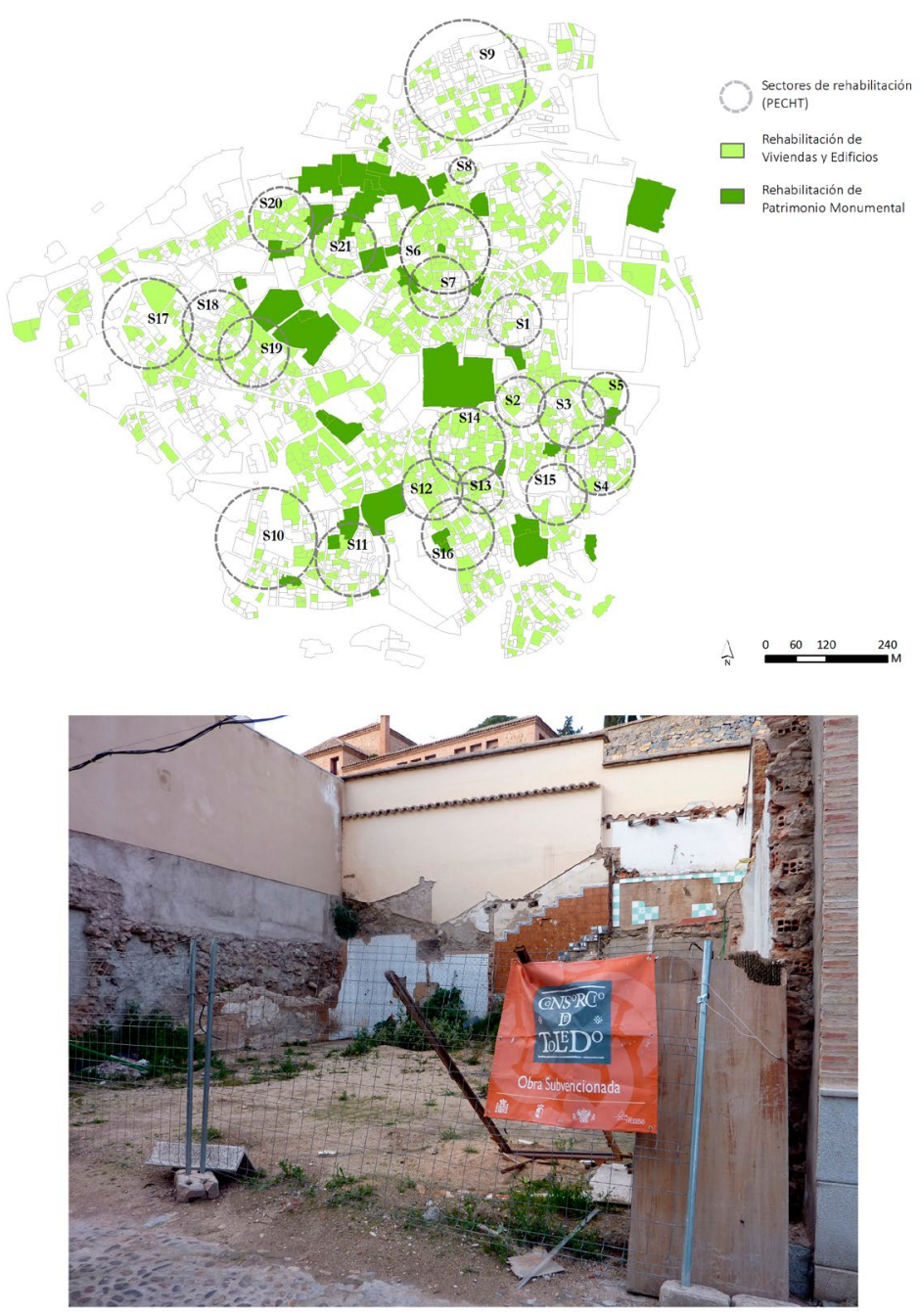

Fuente: reelaborado del Consorcio (2018). Fotografía de Escudero, 12/3/2013. 
910 personas - y cuantitativa - apoyada en el Censo de 2011 y datos catastrales - tiene un carácter generalista, no se tratan de estudios ad hoc orientados a conocer la oferta y los rasgos de sus ocupantes. Por ejemplo, no se sabe con exactitud el número de viviendas existentes, la cantidad de viviendas vacías, su estado, quién las habita, etc. El segundo, el estudio de la demanda no efectúa un análisis profundo de los precios del suelo, precios de alquiler y los procesos de discriminación social que ello genera. En consecuencia, no hay datos que, por ejemplo, permitan estimar de una manera rigurosa el grado de gentrificación. Como advierte Ruiz-Apilánez y Solís (2016) no es solo necesario disponer de un observatorio turístico, como el que se pone en 2006 de la mano del Grupo de Ciudades Patrimonio de la Humanidad (Troitiño, Calle, García y Troitiño, 2007), sino de un observatorio urbano con el objetivo de generar y difundir información turística, económica, social o ambiental $y$, en consecuencia, poder crear un conocimiento más objetivo de los procesos y dinámicas en curso y, guiar y hacer un gestión más eficiente de las políticas y de los recursos económicos.

\subsection{La dinámica demográfica y la función comercial: ¿la vida de barrio en quiebra?}

La función administrativa, docente, cultural y turística no ha frenado la pérdida de población ni la caída de la actividad comercial tradicional en los cascos históricos (Campesino, 1984, 1999; Zárate y Vázquez, 1983; Troitiño et al., 1998; Campos, 1999; Ruiz-Apilánez, Arnáiz y Ureña, 2015).

Como se puede ver en la Tabla 1, el CHT pierde población desde mediados del siglo XX. Desde 1981 hasta 2018, el CHT ha pasado de 17.461 a 10.411 habitantes, perdiendo un total de 7.050 hab. Aunque esta tendencia parece haberse frenado en los últimos años, la situación demográfica al nivel de evolución de la población para el casco histórico es dramática: en 1950 el 84,4\% de la población de la ciudad habitaba en el casco histórico, en 1981 era el 30,2\%, en el 2001 el $15,1 \%$ y en 2018 es el 12,3\%. Hoy, prácticamente solo uno de cada diez toledanos vive en el casco histórico.

Por otro lado, si comparamos los datos publicados por Zárate y Vázquez (1983) y Blanco y Arroyo (2018) respecto a los grupos de edad y nivel educativo, el CHT se caracteriza por: (a) estar sometido a un proceso de envejecimiento más acusado que el resto de la ciudad, la población mayor de 65 años ha pasado de representar el $17,5 \%$ al 19,85\%; mientras que la población con menos de 15 años suponía el $20 \%$ y ahora el 15,53\%; (b) en cuanto a su formación, quien vive presenta un mayor nivel educativo, la población sin estudios y analfabeta ha pasado de representar del $17,5 \%$ al $2 \%$, la población con estudios primarios del $8,2 \%$ al $44 \%$, aquellos con estudios secundarios y profesionales del $21 \%$ al $37 \%$ y la población con estudios superiores del 9,5\% al 19\%. Lo anterior manifiesta la tendencia al envejecimiento y la mejora en el nivel formativo. Dos rasgos sociales que debería motivar a los poderes públicos a repensar temas como la movilidad interna, la repoblación del casco, servicios y equipamientos asistenciales o la promoción de nuevas actividades económicas.

TABLA 1

EVOLUCIÓN DE LA POBLACIÓN

\begin{tabular}{|c|c|c|c|c|}
\hline Año & $\begin{array}{c}\text { Casco histórico } \\
\text { (zona interior de } \\
\text { las murallas) }\end{array}$ & $\begin{array}{c}\text { Resto de } \\
\text { la Ciudad }\end{array}$ & $\begin{array}{c}\text { Total del } \\
\text { municipio } \\
\text { de Toledo }\end{array}$ & $\begin{array}{c}\text { Casco histórico } \\
\text { (\% sobre el } \\
\text { total) }\end{array}$ \\
\hline 1950 & 29.184 & 5.408 & 34.592 & 84,4 \\
\hline 1960 & 26.172 & 14.479 & 40.651 & 64,4 \\
\hline 1970 & 22.169 & 22.213 & 44.382 & 50,0 \\
\hline 1981 & 17.461 & 40.308 & 57.769 & 30,2 \\
\hline 1991 & 12.717 & 50.844 & 63.561 & 20,0 \\
\hline 2001 & 10.332 & 58.050 & 68.382 & 15,1 \\
\hline 2011 & 11.275 & 72.094 & 83.369 & 13,5 \\
\hline 2012 & 11.148 & 72.778 & 83.926 & 13,3 \\
\hline 2013 & 10.786 & 73.002 & 83.788 & 12,9 \\
\hline 2014 & 10.633 & 72.841 & 83.474 & 12,7 \\
\hline 2015 & 10.455 & 72.881 & 83.336 & 12,5 \\
\hline 2016 & 10.447 & 73.172 & 83.619 & 12,5 \\
\hline 2017 & 10.400 & 73.572 & 83.972 & 12,4 \\
\hline 2018 & 10.411 & 74.186 & 84.597 & 12,3 \\
\hline & & & & \\
\hline
\end{tabular}

Fuente: Censos de Población y Padrones. Instituto Nacional de Estadística y Ayuntamiento de Toledo. Elaboración propia.

Desde mediados de siglo la actividad comercial experimenta profundas transformaciones locacionales y estructurales que conduce hacia al desarme funcional de los centros históricos (Zarate y Vázquez, 1988; Campesino, 1999). Aquellos con mayor influencia turística desde los años 80 y 90 del siglo XX experimentan un doble proceso, la pérdida de locales comerciales tradicionales y el incremento de establecimientos hoteleros, restaurantes, cafeterías, bares y tiendas especializadas para el turismo. Esta situación ha motivado, a partir de los años 1990, la puesta marcha diferentes iniciativas para activar el comercio tradicional e impulsar más tiendas para residentes. Tal es el caso de la creación de la Confederación Española de Centros Histórico (COCAHI), la Asociación Española para la Gerencia de los Centros Urbanos (AGECU) o la aparición de 
Asociaciones de Comerciantes de Cascos Históricos. En el caso de Toledo, a pesar de los esfuerzos de la Cámara de Comercio, la Federación de Empresas de Toledo (FEDETO) y el asociacionismo de comerciantes - véase,

FIGURA 5

ACTIVIDADES ECONÓMICAS Y NO ECONÓMICAS EN EL CHT (2014)
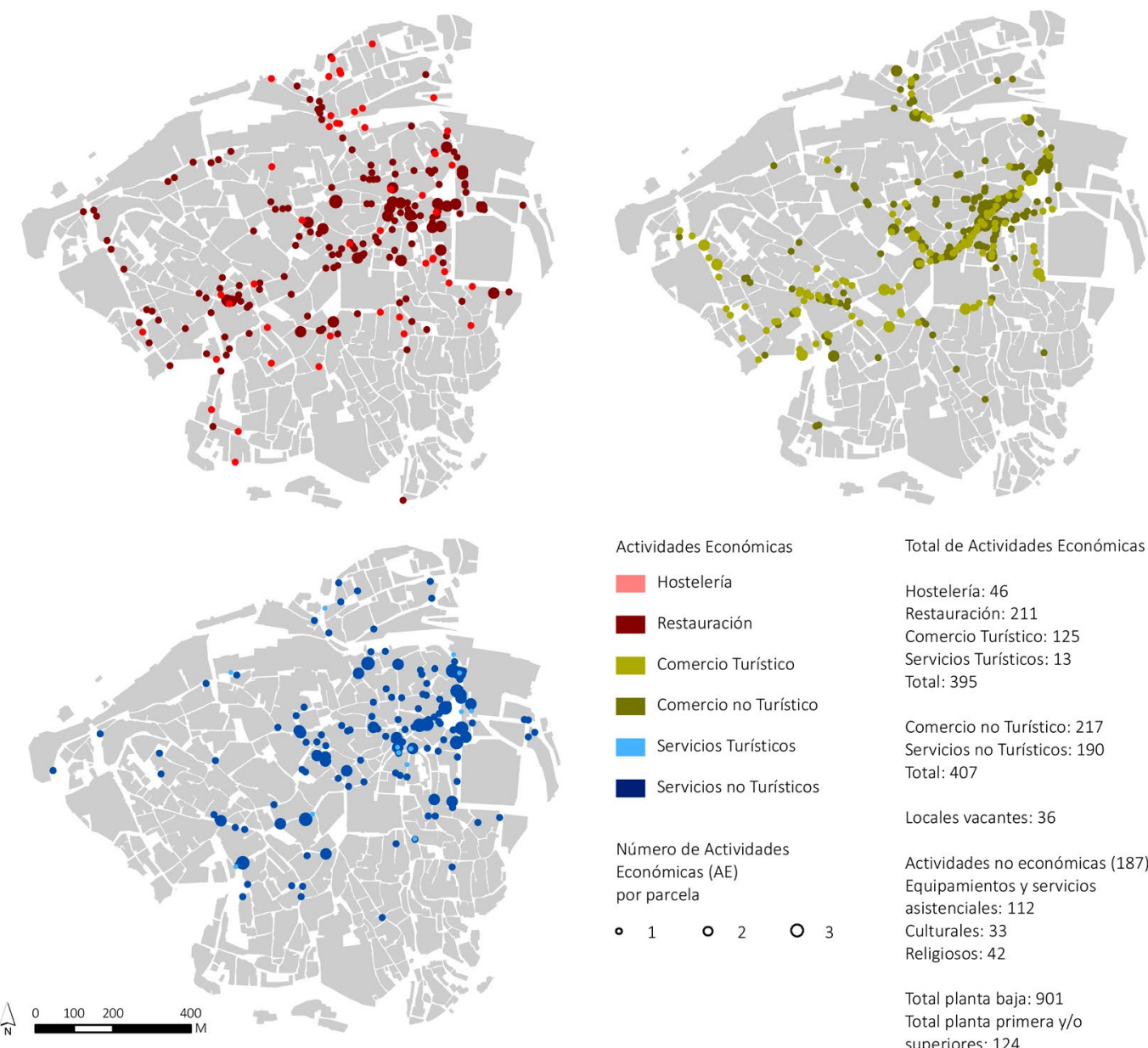

Actividades Económicas

Total de Actividades Económicas

Hostelería

Hostelería: 46

Restauración: 211

Comercio Turístico: 125

Servicios Turísticos: 13

Total: 395

Comercio Turistico

Comercio no Turístico: 217

Servicios no Turísticos: 190

Total: 407

Servicios Turísticos

Servicios no Turísticos

Locales vacantes: 36

Número de Actividades

Económicas (AE)

Actividades no económicas (187)

por parcela

Equipamientos y servicios

asistenciales: 112

- 10203

Culturales: 33

Religiosos: 42

Total planta baja: 901

Total planta primera $\mathrm{y} / \mathrm{0}$

superiores: 124

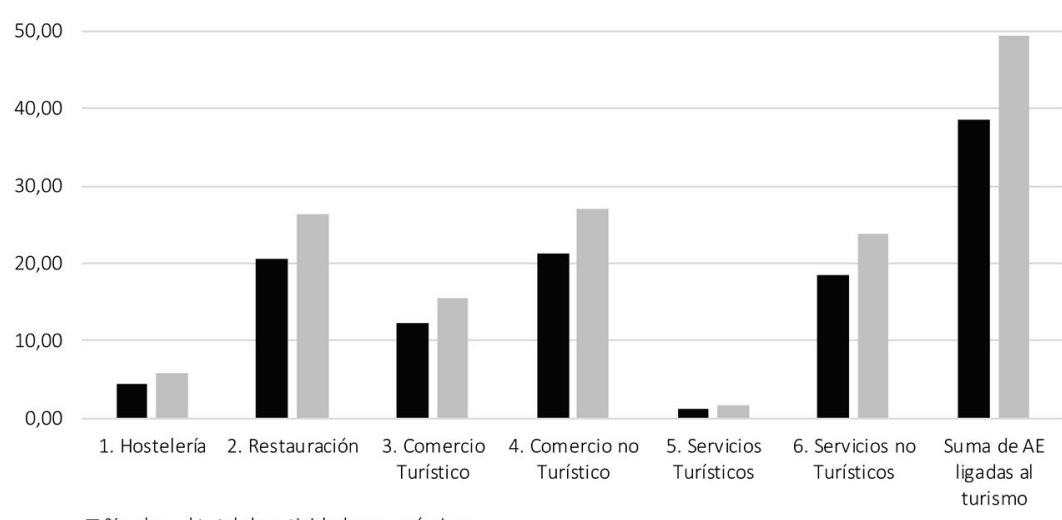

- \% sobre el total de actividades económicas

- \% sobre el total de actividades en PB (excluyendo actividades no económicas y locales vacantes)

Fuente: elaboración propia. 
por ejemplo, Distrito 1-, la quiebra del comercio tradicional - papelerías, droguerías, ferreterías, carnicerías, etc. - sigue agudizándose y con ello perdiéndose la esencia de barrio (Campos, 1999; Monroy, 2015). En relación a este tema, más allá de los diagnósticos elaborados para el PECHT a mediados de los años 1990 (Campos, 1999), el reciente estudio sobre su principal eje urbano, la calle Comercio (Ruiz Apilánez, Arnáiz y Ureña, 2015), o la recurrente voz de alerta de periódicos locales indicando dicha situación, no hay estudios suficientes acerca de los cambios y transformaciones en el comercio en relación a la pérdida del tipo tradicional y sustitución por el vinculado con el turismo.

No obstante, algunos de los autores participaron en un trabajo de campo realizado desde la Escuela de Arquitectura de Toledo en el verano de 2014, en el cual se identificaron todas las actividades económicas y no económicas por parcela en el CHT (los resultados principales se aportan en la Figura 5). En este ejercicio empírico, ya se advertía una consolidación del proceso de turistificación. Del total de actividades económicas y no económicas identificadas (1.025), aquellas vinculadas a la hostelería, restauración, comercio y servicios turísticos ascienden a 395 , lo que representa casi el $40 \%$ del total. Este porcentaje se incrementa al $50 \%$ cuando excluimos las actividades no económicas. Si comparamos estos datos con los aportados por Campos (1999) a mediados de los años noventa, vemos como la turistificación de la economía del CHT se intensifica. Según Campos (1999), las actividades turísticas y de hostelería constituyen el sector con mayor número de establecimientos en el casco histórico, el 30\% del total. Se comprueba que la significación del comercio ligado al turismo ha crecido 20 puntos en veinte años. Desde el punto de vista de la localización, en la Figura 5 se observa una intensa polarización espacial de comercios turísticos y no turísticos en la zona central en el corredor este-oeste. Su ubicación coincide prácticamente con la ruta turística principal que recorren los visitantes de Toledo (cartografiada en Escudero, 2018a, p. 621). Esta polarización es también resultado en buena medida de la zonificación establecida por el PECHT. El plan delimita a lo largo de unos ejes concretos la posibilidad de localizar actividades comerciales. Esta limitación espacial ha supuesto la entrada en "competencia por ubicación» de diferentes actividades comerciales tradicionales y turísticas, siendo estas últimas las más lucrativas y las que han acabado imponiéndose y sustituyendo a las anteriores.

\subsection{El capital fijo: remodelación de espacios públicos y mejoras de la movilidad y accesibilidad}

En las últimas décadas, el espacio público está siendo sometido a un conjunto de intervenciones - mejora de la red de alcantarillado, la iluminación, la peatonalización, la movilidad vertical, la pavimentación, etc. - que se presentan como progreso, pero que, más allá de reducir el número de vehículos u organizar su paso y estacionamiento, tienden a potenciar el consumo y el turismo, suponen un vaciado de contenidos cívicos, una reducción de la diversidad ambiental y apenas generan un verdadero impacto en el confort climático (Nieto, 2012; Brandis y del Río, 2016). En Toledo, con el PECHT de 1998 se puso en marcha un programa de infraestructuras asociado a tres modalidades de actuación: remodelación de calles, plazas y zonas verdes, aparcamientos de borde de carácter disuasorio y mejora de la accesibilidad vertical -escaleras mecánicas-. En la Figura 6 se señalan las principales actuaciones en materia de movilidad y accesibilidad llevadas a cabo y en la Figura 7 se han cartografiado algunas de las realizadas desde entonces y se muestra un ejemplo del sistema de bolardos automáticos que limita la circulación de algunas calles a los vehículos autorizados (residentes, carga y descarga durante horas limitadas, taxis, vehículos oficiales...). Parece que se afianza la idea que el CHT puede y debe vivirse caminando (enfoque para el residente) y puede y debe conocerse, visitarse y utilizarse peatonalmente (enfoque para el turista, trabajador no residente, etc.). A pesar de ello, en materia de movilidad y accesibilidad en el CHT todavía se encuentran algunos retos por delante. La topografía y la sección de ciertas calles limitan el acceso con vehículo privado. Hay zonas en las que se debe revisar la creación de nuevos aparcamientos para residentes. Hasta la fecha, los autobuses existentes hacen una ruta que bordea el casco histórico y no hay itinerarios que conecten distintas áreas internas entre sí. Este aspecto se vuelve más acuciante cuando la población envejece progresivamente, como vimos. Todavía no se ha resuelto la conexión con transporte público entre aparcamientos disuasorios y equipamientos que generan gran movilidad motorizada privada como son los colegios e institutos.

La remodelación efectuada en encuentros de calles, plazas y zonas verdes presenta un diseño que lejos de ofrecer un uso agradable y cómodo para la población residente -áreas de juegos de niños, superficies de suelo permeables, etc. - , tiene una clara vocación 
FIGURA 6

TIPOS DE INTERVENCIONES LLEVADA A CABO EN EL CHT EN MATERIA DE MOVILIDAD Y ACCESIBILIDAD (1997-2019)

$\begin{gathered}\text { Restricciones al uso del transporte privado y creación de aparcamientos dentro y fuera }- \text { aparcamientos } \\ \text { disuasorios - del recinto histórico }\end{gathered}$
$\begin{gathered}\text { Implantación y extensión de los aparcamientos de rotación tipo ORA y su actualización con el pago de tarjeta de } \\ \text { crédito y gestión desde el móvil. }\end{gathered}$
$\begin{gathered}\text { Propuestas para crear nuevas calles peatonales y de coexistencia. Control de acceso a residentes, carga y descarga y } \\ \text { a servicios públicos de transporte y emergencia. }\end{gathered}$
$\begin{gathered}\text { Mejora del transporte público y conexión entre aparcamientos perimetrales con el casco histórico. Construcción de } \\ \text { dos remontes mecánicos. }\end{gathered}$
Reordenación del viario haciéndolo inadecuado para el acceso a los principales puntos de atracción del casco
histórico para los no residentes.

Fuente: elaboración propia.

FIGURA 7

PRINCIPALES TRANSFORMACIONES EN EL ESPACIO PÚBLICO EFECTUADAS DESDE 1998 Y UN EJEMPLO DEL SISTEMA BOLARDOS AUTOMÁTICOS EN EL CHT
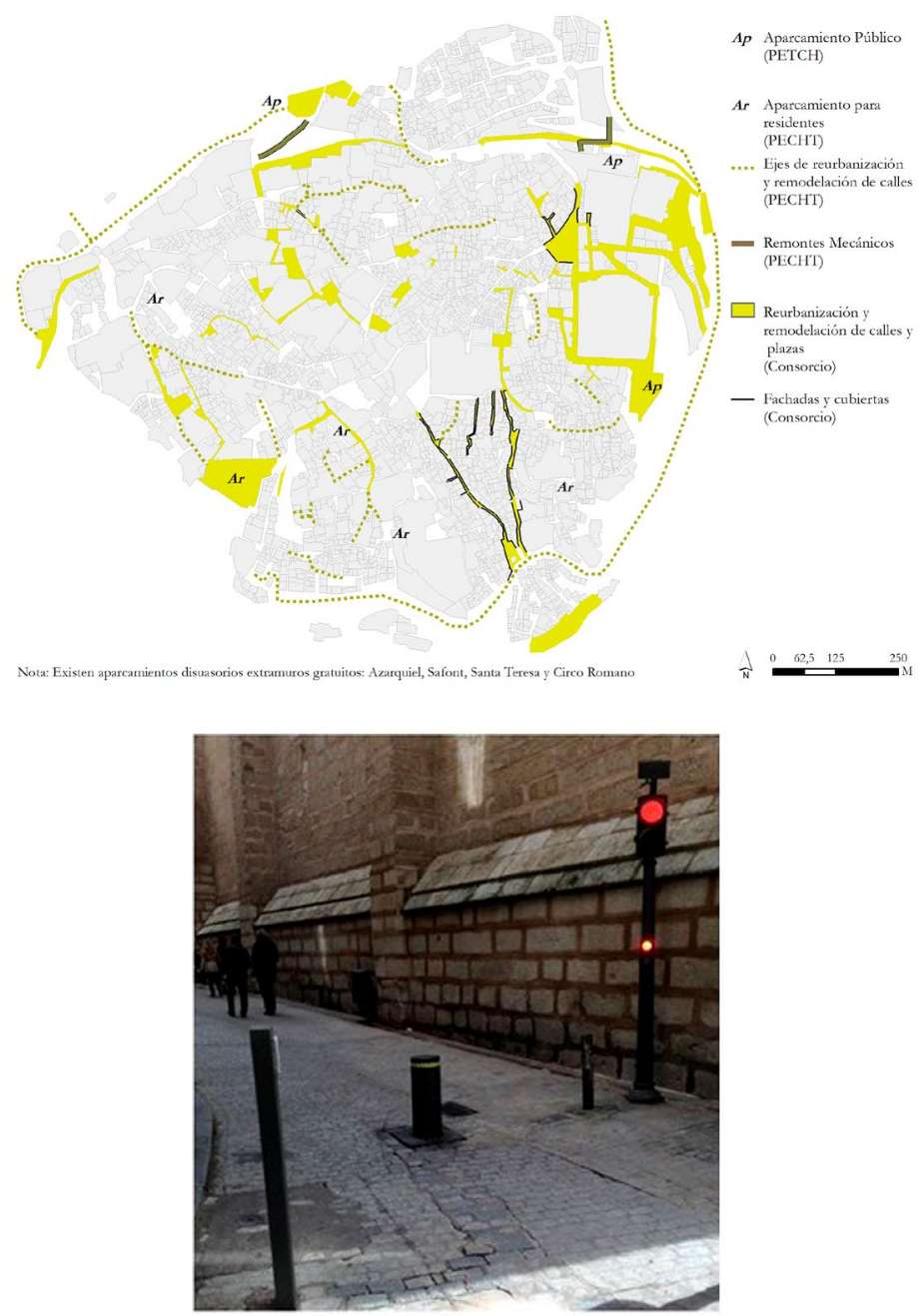

Fuente: elaboración propia y PECHT-1998 y Consorcio (2018). Fotografía de Escudero, 17/2/2015. 
para definir espacios de aparcamiento en superficie y para ser ocupadas por bares, terrazas y restaurantes en favor del consumo y del turismo. En un reciente estudio realizado por Blanco y Arroyo (2018) basado en entrevistas a habitantes del casco histórico, una mujer residente desde 1996 se expresaba sobre esta cuestión de la siguiente manera «A los bares les permiten lo que sea, no puedes pasar por ciertas calles porque está tomada. La Plaza Mayor, ino me digáis! Que la fuente de la plaza mayor esté tomada por las macetas y que esa fuente no pite, que no sea un espacio de los ciudadanos, si no que sea del bar». ( $p$.
42). Así pues, el tradicional simbolismo que la sociedad añade a los espacios públicos queda mermado progresivamente.

\subsection{El turismo: una actividad generadora de riqueza y empleo, pero también de problemas socioeconómicos y ambientales}

La concentración turística en los cascos históricos está generando desajustes y desequilibrios en la trama ur-

TABLA 2

PROBLEMAS DEL TURISMO EN TOLEDO, MEDIDAS ADOPTADAS, SUS RESULTADOS, LAS AMENAZAS Y ERRORES

\begin{tabular}{|c|c|c|c|}
\hline Problema & Medidas & Resultados & Amenazas y errores \\
\hline El excursionismo & $\begin{array}{l}\text { - Plan de Excelencia } \\
\text { Turistica. } \\
\text { - Promoción turística } \\
\text { para el aumento de las } \\
\text { pernoctaciones. } \\
\text { - Visitas nocturnas. } \\
\text { - Pulsera Turística. } \\
\text { - Ayudas públicas al } \\
\text { sector hotelero. } \\
\text { - Implicación de los } \\
\text { agentes turísticos } \\
\text { locales privados. } \\
\text { - Aumento de la oferta y } \\
\text { calidad hotelera. } \\
\text { - Utilización de las } \\
\text { tecnologías de } \\
\text { información, por } \\
\text { ejemplo, páginas Web. }\end{array}$ & $\begin{array}{l}\text {-Aumento de las } \\
\text { pernoctaciones. } \\
\text {-Más plazas hoteleras } \\
\text { disponibles. } \\
\text {-Estancia media del } \\
\text { turista baja. } \\
\text {-Tres excursionistas por } \\
\text { cada turista, en una } \\
\text { estimación realista. } \\
\text {-Resultados } \\
\text { insuficientes. }\end{array}$ & $\begin{array}{l}\text { - El área urbana de } \\
\text { Madrid. } \\
\text { - Los operadores } \\
\text { turísticos. } \\
\text { - Falta de implicación de } \\
\text { los agentes turísticos } \\
\text { privados no locales } \\
\text { (madrileños y globales, } \\
\text { fundamentalmente). } \\
\text { - El tren de alta velocidad. } \\
\text { - Error: campañas de } \\
\text { promoción fallidas. }\end{array}$ \\
\hline $\begin{array}{l}\text { Limitado uso de } \\
\text { los bienes } \\
\text { patrimoniales } \\
\text { (masificación) }\end{array}$ & $\begin{array}{l}\text { - Pulsera Turistica. } \\
\text { - Nuevos productos } \\
\text { turísticos: rutas. } \\
\text { - El Patrimonio } \\
\text { Desconocido del } \\
\text { Consorcio de Toledo. } \\
\text { - Promoción turística. }\end{array}$ & $\begin{array}{l}\text { - Ampliación de la } \\
\text { puesta en valor turístico } \\
\text { del patrimonio. } \\
\text { - Nuevos lugares } \\
\text { patrimoniales visitables. } \\
\text { - Productos turisticos } \\
\text { novedosos. } \\
\text { - Resultados } \\
\text { insuficientes. }\end{array}$ & $\begin{array}{l}\text { - Masificación y } \\
\text { saturación derivada del } \\
\text { turismo en los principales } \\
\text { atractivos patrimoniales } \\
\text { de la ciudad. } \\
\text { - Error: fuerte inversión } \\
\text { para resultados limitados, } \\
\text { como en el programa EI } \\
\text { Patrimonio Desconocido. }\end{array}$ \\
\hline $\begin{array}{l}\text { Accesibilidad y } \\
\text { movilidad } \\
\text { complicadas }\end{array}$ & $\begin{array}{l}\text { - Aparcamientos } \\
\text { subterráneos de pago. } \\
\text { - Aparcamientos } \\
\text { disuasorios al aire libre, } \\
\text { alejados pero gratuitos. } \\
\text { - Remontes al centro } \\
\text { histórico a través de } \\
\text { escaleras mecánicas. } \\
\text { - Restricción del tráfico } \\
\text { en algunas zonas } \\
\text { (pivotes automáticos). } \\
\text { - Áreas externas para } \\
\text { aparcamiento y } \\
\text { descarga de los } \\
\text { autobuses. } \\
\text { - El Centro de } \\
\text { Recepción de Visitantes. }\end{array}$ & $\begin{array}{l}\text { - Mejora de la movilidad } \\
\text { peatonal en el centro } \\
\text { histórico. } \\
\text { - Mejora de la } \\
\text { accesibilidad peatonal. } \\
\text { - Disuasión positiva con } \\
\text { el sistema de } \\
\text { aparcamientos. } \\
\text { - Quiebra del Centro de } \\
\text { Recepción de Visitantes. } \\
\text { - Tapones de tráfico en } \\
\text { los accesos con } \\
\text { regularidad. } \\
\text { - Resultados } \\
\text { insuficientes. }\end{array}$ & $\begin{array}{l}\text { - El poder del automóvil } \\
\text { como principal medio de } \\
\text { transporte en nuestra } \\
\text { sociedad. Al centro } \\
\text { histórico van los } \\
\text { visitantes, pero también } \\
\text { sus residentes y sus } \\
\text { trabajadores con sus } \\
\text { vehículos particulares. } \\
\text { - Siguen accediendo } \\
\text { autobuses al centro } \\
\text { histórico. } \\
\text { - Muchos automovilistas } \\
\text { continúan intentando } \\
\text { aparcar en el centro } \\
\text { histórico. } \\
\text { - Desconocimiento de los } \\
\text { recién llegados. } \\
\text { - Error: Enorme malgasto } \\
\text { de la inversión pública en } \\
\text { el fallido Centro de } \\
\text { Recepción de Visitantes. }\end{array}$ \\
\hline
\end{tabular}


bana clásica (Marín, Guevara y Navarro-Jurado, 2017). El CHT es un destino turístico cultural y patrimonial principal dentro de España. El desarrollo del turismo ha supuesto un conjunto de realidades y problemáticas que previamente han sido tratadas por uno de los autores (Escudero, 2018a) y en la tabla 2 se sintetizan.

De manera general, progresivamente asistimos a la consolidación de los cascos históricos como espacios de consumo turístico cultural, ligado en buena medida a la contemplación y disfrute del patrimonio histórico. Ello ha supuesto que las ciudades históricas y patrimoniales se vayan transformando y preparando para acomodar dos subsistemas: (a) el patrimonio arquitectónico monumental y popular, así como los espacios públicos y paisaje asociado, y (b) los servicios de acogida de la ciudad constituidos desde la oferta restauración, alojamiento, así como comercios, talleres o fiestas (De la Calle y García, 1998). La herencia arquitectónica y urbana ligada en el caso de Toledo a la cultura musulmana, hebrea y cristiana ${ }^{14}$ junto a su condición histórica de centralidad territorial, hace que hoy cuente con 97 Bienes de Interés Cultural ${ }^{15}$. A esta riqueza patrimonial hay que sumar las exposiciones permanentes y temporales que acoge la ciudad y las festividades que se celebran, en concreto la Semana Santa y el Corpus declaradas ambas Fiestas de Interés Turístico Internacional, así como las numerosas actividades para conectar gastronomía, cultura y turismo. Según el Observatorio de Ciudades Patrimonio de la Humanidad, a fecha de 2018, la ciudad de Toledo cuenta con 63 establecimientos hoteleros, 4.310 habitaciones en hotel y 375 apartamentos turísticos. Teniendo en mente las oportunidades económicas que brinda el turismo, hay importantes retos que encarar (Tabla 2). Están derivados la especialización de la actividad económica ligada al turismo o turistificación, de la gestión de flujos turísticos ante la presión, saturación y congestión turística y de la tendencia hacia la museificación. Es decir, se produce un elevado riesgo de la desaparición de la vida urbana marcada por los ritmos cotidianos asociados a residentes sustituida por unos ritmos vinculados al turista (Troitiño et al., 1998; Troitiño y Troitiño, 2010; Troitiño, 2012; Pulido, De la Calle y Velasco, 2013; Blanco y Arroyo, 2018).

\subsection{La gestión de los cascos históricos: la coordinación y la regulación como retos pendientes}

Los cascos históricos se han visto envueltos en la falta de coordinación en el ámbito urbanístico, patri- monial y económico a diversas escalas (Troitiño, 1992; 2012; Pol, 2015; García, 2007). Este desajuste en el caso de Toledo se inicia en los años 40 del siglo XX y se prolonga durante todo el siglo con la desconexión entre los Planes Generales de Ordenación Urbana (PGOU) (1943, 1964 y 1986), las ordenanzas para el casco histórico de 1943, las Instrucciones de Bellas Artes de 1968 y el PECHT de 1997 (Zárate y Vázquez, 1983; Busquets, 2000; Zárate, 2007; Almarcha, Sánchez, Peris y Diez de Baldeón, 2011; Aparicio y Martínez, 2015; Aparicio, Serrano y León, 2018; RuizApilánez y Solís, 2016; Escudero, 2018b). A fecha de 2018, el Ayuntamiento de Toledo aprobó una resolución que le otorgaba la potestad de dirigir las ordenanzas del PECHT, sustituyendo las instrucciones aprobadas por orden ministerial de 23 de julio de 1968. Cabe señalar que esta resolución vincula cualquier actividad urbanística al PGOU de 1986, ya que el Plan de Ordenación Municipal (POM) de 2007, último plan urbanístico de la ciudad quedó anulado por el Tribunal Constitucional en 2017, tras diversas resoluciones y recursos. Nos encontramos ante la necesidad de redactar un nuevo plan de ordenación municipal y un nuevo plan especial para el casco histórico, sin dejar al margen, en nuestra opinión, (1) la condición de Toledo como nodo principal de un área urbana plurimunicipal, como capital regional, como subcentro de la región urbana madrileña y como destino global del turismo (Solís, Mohíno y Ureña, 2018) y (2) la coordinación de las diferentes entidades de gestión turística local - concejalías, delegaciones, áreas de turismo, los organismos autónomos de capital público (con o sin participación privada), instituciones con funciones específicas respecto a la promoción turística (Fundación Toledo Ciudad de Congresos, Spain Convention Bureau, etc.), el Consorcio y las estructuras supralocales de gestión conjunta (Club Ciudades Patrimonio de la Humanidad, Red de Juderías, Red de Ciudades AVE, etc.) (Fig. 8).

En paralelo a esta situación, los cascos históricos han ensayado diversos caminos en la gestión del planeamiento especial: comisiones de seguimiento, operaciones de actuación conjunta, agencias de renovación urbana, empresas mixtas y consorcios (Troitiño, 2003a). Toledo cuenta, junto a las Comisiones de Patrimonio, con la Real Fundación -institución cultural privada creada en 1988-, el Real Patronato - establecido en 1998- y el ya citado Consorcio creado en 2001-. Aunque el Consorcio ha trabajado en la coordinación entre el Estado, la Junta de Comunidades de Castilla-La Mancha, la Diputación de Toledo y el Ayuntamiento, ha tenido una mayor relación 
FIGURA 8

LAS ESCALAS DE INTERVENCIÓN EN EL CHT: DE LA COORDINACIÓN VERTICAL A LA COORDINACIÓN HORIZONTAL

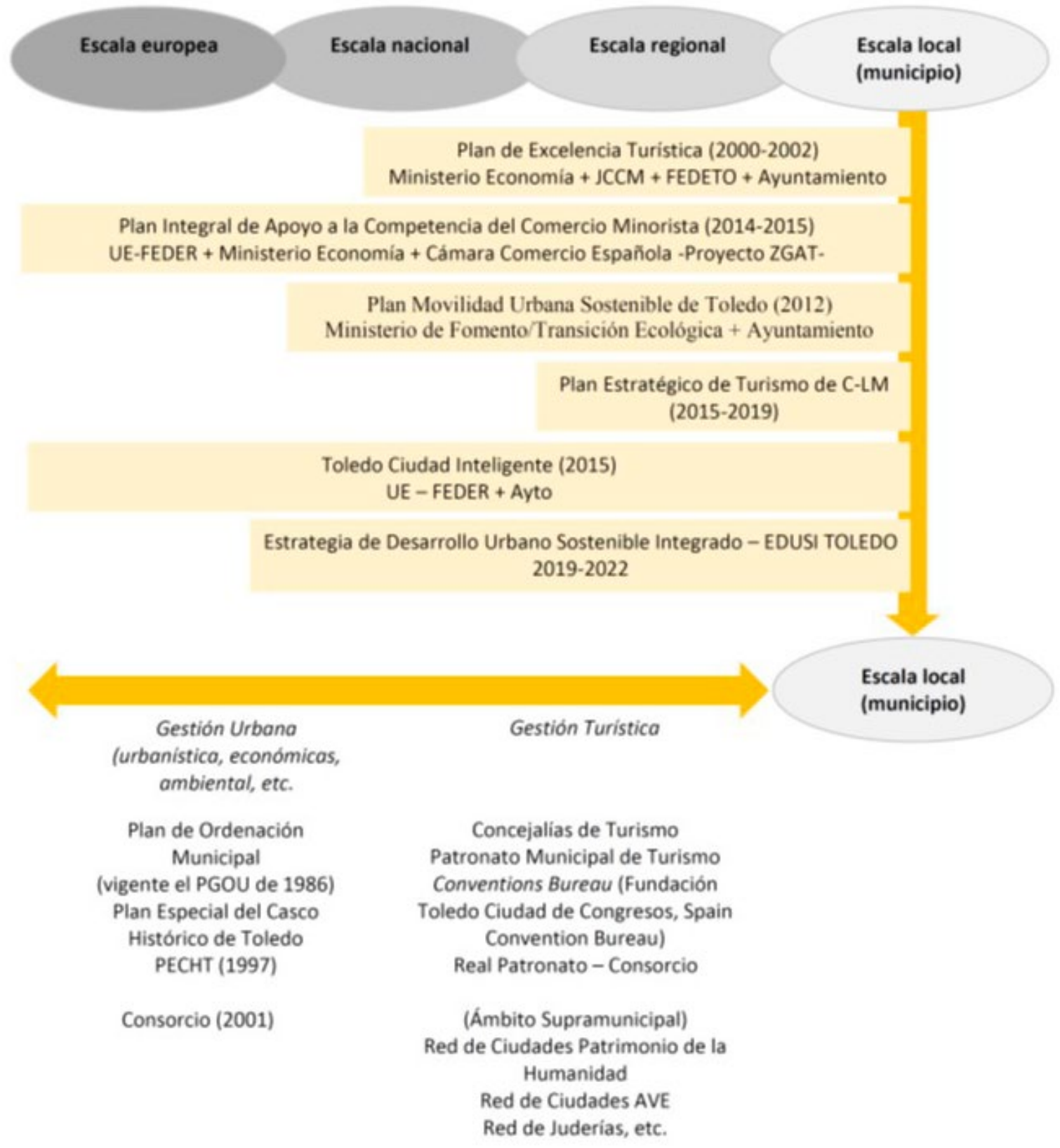

Fuente: Elaboración propia.

con este último. Ello ha posibilitado la puesta en marcha de ordenanzas - Ordenanza Reguladora de Publicidad y Rotulación en el casco histórico, la revisión del Catálogo del Plan Especial, la Ordenanza de Locales Comerciales ${ }^{16}$, el Plan de Conservación de Elementos Especiales y el Plan de Color del PECHT-e inventarios - de morteros de revestimiento, de por- tadas y escudos, de carpinterías de armar y taller, de arbolado...-. A pesar de ello, la labor de coordinación es una tarea pendiente y clave no solo para el $\mathrm{CHT}$ sino para la ciudad en la que se inserta.

Si el mal estado de conservación de los edificios, la inadecuación de su tejido urbano para el uso automovilístico, la ausencia de dotaciones básicas (es- 
cuelas, ambulatorios, comercios, zonas verdes) y la falta de condiciones higiénicas elementales entre otros factores motivó durante décadas la pérdida de población en los cascos históricos, ¿por qué la gran inversión efectuada en las dos últimas décadas en la mejora de infraestructuras y del estado de los edificios no ha motivado la repoblación? Obviamente, no hay una respuesta única ni sencilla. Realmente, existe una repoblación, pero no de población residente sino temporal, ya sea por motivos de trabajo, ocio, educación, segunda residencia o turismo. Se puede afirmar que el $\mathrm{CHT}$ ha contado con políticas y fondos públicos que han permitido una transformación física y una revitalización funcional y social, pero que carece de justicia social y espacial. La museificación, turistificación y gentrificación son tres fenómenos de esta realidad. La administración y agentes privados se interesan más por el empleo y el gasto del turista o en qué servicios ofrecer y en cómo organizar y disponer la ciudad para que los visitantes se queden más tiempo, consuman más y repitan su experiencia, que por apostar por un espacio donde se ofrezca una gama amplia de posibilidades para residir, un espacio público para estar, jugar, pasar el tiempo, debatir, etc. y por funciones múltiples que aseguren la vida de las calles y plazas, más allá de su consumo turístico.

\section{CONCLUSIONES}

A la luz de las tendencias observadas, el $\mathrm{CHT}$ presenta rasgos físicos relativos a la forma, densidad, compacidad o diversidad tipológica propios del modelo urbano sostenible, mientras que los rasgos socioeconómicos y funcionales se alejan del paradigma de la sostenibilidad.

i. La pérdida de población en el CHT y el incremento de turistas evidencia el grado de museificación progresivo que vive la ciudad. Si en 1998 se contabilizaban 1,5 millones de visitantes y había 10.332 residentes y en 2018 la cifra de turistas y excursionistas se aproxima a los $3 \mathrm{mi}-$ llones y el CHT tiene 10.411 residentes, Hemos pasado de una ratio visitante/residente de 145,1 en 1998 a 287,3 en 2018. Estos datos muestran la clara estrategia de convertir el CHT en un contenedor espacial de entretenimiento y consumo para los visitantes.

ii. Asistimos a una transformación del espacio físico que, vía inversión inmobiliaria e infraestructural, genera una revalorización económica del precio de suelo - ya sea de compraventa, de alquiler residencial o de uso turístico de la vivienda-, que para nada está vinculada con una oferta de alquiler residencial asequible o se orienta a generar vivienda pública (Escudero, 2018b). Es claro el proceso de mercantilización del espacio urbano y el emergente proceso de gentrificación asociado.

iii. El CHT está sometido a un proceso turistificación, es decir, de especialización de actividades económicas ligadas al sector turístico. Se hace evidente que los agentes públicos y privados en connivencia han apoyado y apoyan una estrategia orientada al turismo, al consumo temporal de la ciudad.

Parece que la advertencia de Rem Koolhaas en La ciudad genérica (1994) sobre los riesgos de exacerbar el sentido de identidad y de reducir las funciones tiende a consolidarse en los cascos históricos. Estamos ante una situación en la que progresivamente se va perdiendo mezcla social y plurifuncionalidad. Las administraciones y organismos públicos han puesto en marcha políticas e instrumentos que, bajo la bandera de la protección del patrimonio, la recuperación urbana y la revitalización hacen que los cascos históricos se conviertan en espacios al servicio de capitalismo.

La ciudad de Toledo no sólo participa de un modelo territorial multicéntrico a escala intrametropolitana (Solís, Mohíno y Ureña, 2018) sino que además internamente tiene varios espacios de centralidad, entre ellos, el CHT (Zárate, 2007; Escudero, 2018b). Este hecho debería ser potenciado en dos sentidos. El primero, establecer una estrategia que permita la localización de actividades económicas ligadas a la economía del conocimiento. El segundo, ampliar la gama de opciones para residir y vivir de forma permanente en el CHT. Heidegger (2015) decía que la ciudad sin residentes permanentes, sin habitantes propios, no era ciudad, pues la ciudad es producto del cuidado de sus habitantes, de su construcción de siglos y siglos para procurarse una casa pero también un hábitat (en Ordoñez, 2017:148). Los poderes públicos no deben dejar en manos del mercado el suministro de un aspecto tan vital como es la vivienda.

Finalmente, planteamos algunos temas a tratar en el futuro. El primero, es preciso estudiar el fenómeno de la vivienda con uso turístico, su lógica espacial y su relación con las reformas efectuadas en viviendas y edificios con inversión público (por ejemplo, Con- 
sorcio) e inversión privada. ¿En qué medida la inversión pública se convierte en vehículo para la especulación, museificación, turistificación, etc.? El segundo, reconociendo la capacidad del turismo para ejercer de motor de desarrollo económico y generación de empleo, poco se sabe sobre las redes de empresas locales y supralocales conectadas al turismo, sueldos, condiciones laborales, necesidades formativas, etc. El tercero, analizar la capacidad de carga o saturación en ciertos monumentos, ámbitos espaciales y rutas

\section{NOTAS}

1 La noción de centro urbano también puede interpretarse como localización relativa, derivada por la accesibilidad y el sistema viario. Como han señalado Castells y Borja (1997), el centro urbano no puede ser considerado como una entidad espacial definitiva, sino como una reunión de funciones y actividades que desempeñan un papel de intercomunicación entre los diversos elementos de la estructura urbana.

2 Según la Ley 16/1985, de 25 de junio, del Patrimonio Histórico Español, los conjuntos históricos son Bienes de Interés Cultural que se refieren a agrupación de bienes inmuebles que forman una unidad de asentamiento, continua o dispersa, condicionada por una estructura física representativa de la evolución que ha tenido una comunidad humana, por ser testimonio de su cultura o porque constituya un valor de uso y disfrute para la colectividad, aunque individualmente no tengan una especial relevancia. Asimismo, es conjunto histórico cualquier núcleo individualizado de inmuebles comprendidos en una unidad superior de población y que reúna esas mismas características y pueda ser claramente delimitado.

3 Córdoba (1929), Granada (1929), Toledo (1940) y Santiago de Compostela (1940) fueron las primeras ciudades españolas declaradas Conjunto Histórico Artístico.

4 Estos 2,6 kilómetros cuadrados engloban toda la zona intramuros, además de las riberas del Tajo que bordean el casco y parte del arrabal de las Covachuelas.

5 Con un libro publicado en 1952 y editado por Ernesto Nathan Rogers, Josep Lluís Sert y Jaqueline Tyrwhitt, que informa del debate que tuvo lugar en Hoddesdon (Reino Unido) entre el 7 y el 14 de julio de 1951 durante el CIAM VIII. en Toledo, con el objeto de repartir espacialmente los flujos turísticos y evitar los efectos negativos de la excesiva concentración turística. El cuarto, estudiar y articular estrategias respecto al número de viviendas secundarias y vacías, edificios en ruinas y bienes inmuebles que tienen protagonismo en el espacio urbano y pierden funcionalidad y significación en la economía urbana - por ejemplo, los espacios conventuales en Toledo-.

6 Victor Gruen en The heart of four cities. The urban crisis: diagnosis and cure (1965), manifiesta que "lo que hace latir el corazón de una ciudad, no son sus estructuras, ni sus servicios, ni sus vehículos, sino la gente que invade la ciudad en múltiples formas, porque de lo contrario sus estructuras se convierten en cáscaras huecas carentes de significado» (en Ordoñez, 2017). Reconoce el valor de estas estructuras, pero manifiesta que este trasciende a su materialidad. Gruen utilizaría sus estudios para dotar de corazones a las periferias que carecían de vitalidad urbana.

7 En la versión no publicada del discurso de apertura de Sert para el CIAM VIII observó que la mayoría de las personas en las ciudades se han marchado a los suburbios, correspondiendo a la tendencia de descentralización en las ciudades. De forma tal que si queremos hacer algo con nuestras ciudades tenemos que hablar de nuevo en términos cívicos y urbanos. Para Sert, la única ventaja real de vivir en una ciudad es acercar al hombre con el hombre, y hacer que la gente intercambie ideas y sea capaz de discutirlas de forma libre (en Frampton y Mumford, 2000).

8 Las ideologías del planeamiento funcionalista consideraban que los tejidos urbanos históricos eran rémoras de un pasado urbano ineficiente, desajustado e insalubre, y por tanto como objetos de necesarias reformas, de alcance a veces extremo, más allá de la casi rutinaria aceptación de la preservación de los grandes episodios monumentales.

9 A partir de los años 80 del siglo XX, a través de organismos internacionales como el Consejo de Europa mediante la Campaña para la Recuperación de la Ciudad (1980) y la UNESCO promotora de la Carta Internacional de las Ciudades Históri- 
cas (1986) se define un conjunto de actuaciones conocidas bajo el rótulo de políticas de rehabilitación integral. La preocupación es atender tanto al espacio edificado (espacio público y espacio privado) y al tejido social como a los equipamientos y al transporte.

10 El Congreso de Bérgamo de 1971 estuvo organizado por la asociación nacional para los centros históricos italiana para debatir sobre la relación entre residencia popular y centro histórico (Álvarez, 1993).

11 En una entrevista periodística de M. Pérez en Eldiario.es con fecha de 24 de enero de 2016. Recuperado de: https://www.eldiario.es/galicia/ politicas-publicas-vivienda-pendiente-historico_ 0_476652616.html (5 de febrero de 2019).

12 Se trata de un programa que se inicia en 1989 y tiene por objetivo la rehabilitación integral de la ciudad como hecho global. En el caso de Toledo las subvenciones se prolongan desde 1989 hasta 1994. Este programa se articula en torno a cinco subprogramas: la rehabilitación de viviendas, la mejora del paisaje urbano, la potenciación del equipamiento sociocultural, la restauración monumental y la redacción del Plan Especial. Véase el artículo de Campos (1991) para profundizar en las actuaciones llevadas a cabo en Toledo para este momento.

13 Según Campos (1998: 259-260) el programa Toledo a Plena Luz impulsado por la Consejería de

\section{REFERENCIAS BIBLIOGRÁFICAS}

Almarcha, E., Sánchez, I., Peris, D. y Diez de Baldeón, P. (2011). Paisaje de los conjuntos históricos: Castilla-La Mancha. Centro de Estudios de Castilla-La Mancha.

Álvarez, A. y Roch, F. (1980). Los centros urbanos: hacia la recuperación popular de la ciudad. Madrid, España: Nuestra Cultura.

Álvarez, A. (1993). La renovación de los centros urbanos como práctica ideológica. Ciudades, 1, 19-35.

Álvarez, A. (1999). El uso del espacio del centro histórico de Segovia en el marco de los programas de renovación y conservación de su contenido patrimonial. En A. Campesino (Coord.), Comercio, turismo y cambios funcionales en las ciudades
Cultura a fecha de 1998 habría recuperado más de 600 viviendas particulares. Desde la aprobación del PECHT en 1997, gracias a la firma alcanzada con el Ministerio de Fomento, la Consejería de Obras Públicas y el Ayuntamiento de Toledo establecieron un convenio para un total de 900 actuaciones entre 1998-2001. Parte de estas actuaciones (un total de 36) también estuvieron sufragadas por fondos europeos.

14 Una de las imágenes turísticas más difundidas de Toledo es la de "la Ciudad de las Tres Culturas», con una idea de tolerancia idílica y de convivencia armónica en el medievo se ha creado esta marca (Escudero, 2018c).

15 Según el Ayuntamiento de Toledo, hay 98 BICs dentro del ámbito del PECHT, 97 si quitamos el propio casco histórico. Sumados los 12 BIC que se encuentran fuera del ámbito del plan, contamos un total de 109 BICs. En el siguiente enlace pueden identificarse los bienes culturales en Toledo https://www.toledo.es/servicios-municipales/ urbanismo/proteccion-del-patrimonio-cultural/ bienes-de-interes-cultural/los-bic-de-toledo/ (5 de junio de 2019).

16 El Consorcio ofrece ayudas a los locales comerciales que quieran mejorar su imagen exterior o arreglar sus instalaciones básicas de agua, luz, alcantarillado, climatización, telefonía, comunicaciones y elementos de seguridad y protección.

españolas patrimonio de la humanidad (pp. 111131). Cáceres, España: Cámara Oficial de Comercio e Industria de Cáceres.

Álvarez, A. (2001). La cuestión de los cascos históricos: generación de planes y políticas urbanísticas recientes. En M. Castillo (Coord.), Ciudad, territorio y patrimonio: materiales de investigación: programa de doctorado enero 1999-diciembre 2000 (pp. 13-30). Valladolid, España: Universidad de Valladolid.

Álvarez, A. (2011). El comportamiento de los conjuntos históricos en el marco de las dinámicas demográficas e inmobiliarias de alcance territorial: el caso de los núcleos urbanos de Castilla. Ciudades, 14, 111-131. 
Aparicio, A. E., Serrano, O. y León, D. (2018). Rehabilitación y reutilización del patrimonio urbano. Los cascos históricos de nuevas capitales políticas españolas. Cuadernos de Turismo, 42, 15-45.

Aparicio, A. E. y Martínez, J. M. (2015). Rehabilitación y reutilización del patrimonio urbano al servicio de las funciones de la capitalidad autonómica. Análisis comparado de Toledo y Pamplona. Boletín de la Asociación de Geógrafos Españoles, 69, 387-414.

Bailey, N. y Robertson, D. (1997). Housing renewal. Urban policy and gentrification. Urban Studies, 34 (4), 561-578.

Blanco, R. y Arroyo, L. (2018). Geografía humana del Casco Histórico de Toledo. Estilos de vida y su transformación. En J. Manzano (Ed.), Casco Histórico de Toledo. Construir la convivencia ( $\mathrm{pp}$. 7-69). Toledo, España: Toletum Revolutum.

Bonet, A. y Gavira, C. (1987). Transformación del centro y percepción del espacio urbano. Estudios sobre Espacios Urbanos (pp. 671-676). Madrid, España: Casa de Velázquez.

Brandis, D. y del Río, I. (2016). Paisaje y espacio público urbano. El deterioro de las plazas del centro histórico madrileño (1945-2015). Cuadernos Geográficos, 55, 1, 238-263.

Busquets, J. (2000). Toledo y su futuro el plan especial del casco histórico. Toledo, España: Ayuntamiento de Toledo.

Camarena, M. (2018). Turistificación o vida de barrio. El problema de las viviendas de uso turístico en el Casco Histórico de Toledo. En J. Manzano (Ed), Casco Histórico de Toledo. Construir la convivencia (pp. 125-150). Toledo, España: Toletum Revolutum.

Campesino, A. (1984). Los centros históricos. Análisis de su problemática. Norba, Revista de Geografía, 5, 51-61.

Campesino, A. (1989). Rehabilitación integrada de los cascos históricos: el reto urbanístico de finales de los ochenta. Investigaciones Geográficas, 7, 7-17.

Campesino, A. (Coord.) (1999). Comercio, Turismo y Cambios Funcionales en las Ciudades Españolas Patrimonio de la Humanidad. Cáceres, España: Cámara Oficial de Comercio e Industria de Cáceres.

Campos, M. L. (1991). Toledo A Plena Luz. Un programa de rehabilitación. Anales de Geografía de la Universidad Complutense, 11, 217-223.
Campos, M. L. (1998). La funcionalidad residencial. En J. García y M. Troitiño (Eds.), Vivir las ciudades históricas: recuperación integrada y dinámica funcional (pp. 257-262). Cuenca, España: Universidad de Castilla-La Mancha.

Campos, M. L. (1999). Transformaciones del comercio minorista del centro histórico de Toledo, inducidas por los actuales cambios funcionales. En A. Campesino (Coord.), Comercio, turismo y cambios funcionales en las ciudades españolas Patrimonio de la Humanidad (pp. 133-160). Cáceres, España: Cámara de Comercio e Industria.

Campos, M. L. (2002). Análisis del turismo en CastillaLa Mancha en el umbral del nuevo milenio. En M. L. Campos (Coord.), El turismo en Castilla-La Mancha: análisis y prospectiva (pp. 69-102). Cuenca, España: Universidad de Castilla-La Mancha.

Capel, H. (1975). Capitalismo y morfología urbana en España. Barcelona, España: Universidad de Barcelona.

Capel, H. (2007). El debate sobre la construcción de la ciudad y el Ilamado "Modelo Barcelona". Scripta Nova. Revista Electrónica de Geografía y Ciencias Sociales, XI (233).

Carrión, F. (2012). Aproximación distante a los paisajes culturales: el caso de los centros históricos. En Paisajes Culturales: Reflexiones conceptuales y metodologías. Memorias del I Encuentro de Expertos (pp. 51-60). Quito, Ecuador: Ministerio de Cultura y Patrimonio.

Castells, M. (2002). La cuestión urbana. Ciudad de México, México.

Castells, M. y Borja, J. (1997). Lo local y lo global: la gestión de las ciudades en la era de la información. Madrid, España: Grupo Santilla de Ediciones.

Cervellati, P. L. y Scannavini, R. (1976). Bolonia: política y metodología de la restauración de centros históricos. Barcelona, España: Gustavo Gili.

Consorcio de la Ciudad de Toledo (2018). Pasión por Toledo. 15 años del Consorcio de la Ciudad de Toledo. Toledo, España: Consorcio de Toledo.

Culot, M. (1988). La Vuelta al Pasado: Una Aventura de Creación. En VV.AA. Arquitectura y Urbanismo en Ciudades Históricas (pp. 24-44). MOPU-UIMP. 
De la Calle, M. y García, M. (1998). Ciudades históricas: patrimonio cultural y recurso turístico. Ería, $47,249-266$.

De Moura, J. de (2001). The historical city as the sustainable compact city model. En Proceedings of the 6th International Symposium of World Heritage Cities (pp. 231-239). Puebla, México: Organisation Villes du Patrimoine Mondial.

Dürr, E. y Jaffe, R. (2012). Theorizing slum tourism: Performing, negotiating and transforming inequality. European Review of Latin American and Caribbean Studies, 93, 113-123.

Escudero, L. A. (2018a). Realities and problems of a major cultural tourist destination in Spain, Toledo. Pasos. Revista de Turismo y Patrimonio Cultural, 16 (3), 617-636.

Escudero, L. A. (2018b). Procesos de urbanización difusos y estructuras urbanas fragmentadas: el caso de Toledo (Castilla-La Mancha, España). Ciudad y Territorio. Estudios Territoriales, L (197), 517-538.

Escudero, L. A. (2018c). The construction and perception of cultural tourism images and brands. A case study from Toledo (Spain). Lusophone Journal of Cultural Studies, 5 (2), 61-82.

Estébanez, J. (1989). Las ciudades, morfología y estructura. Madrid, España: Síntesis.

Ferrer, M. (2003). Los centros históricos en España. Pamplona, España: Gobierno de Navarra.

Fezzai, S, Mazouz, S. y Ahriz, A. (2015) Sustainable urban design of historical city centers. Energy Procedia, 74, 301-307.

Frampton, K. y Mumford, E. (2000). The CIAM Discourse on Urbanism, 1928-1960. Cambridge, MA, Estados Unidos: Massachusetts Institute of Technology.

García, C. (2004). Ciudad hojaldre. Visiones urbanas del siglo XXI. Barcelona, España: Gustavo Gili.

García, M. (2000). Turismo y medio ambiente en ciudades históricas: de la capacidad de acogida turística a la gestión de los flujos de los visitantes. Anales de Geografía de la Universidad Complutense, 20, 131-148.

García, M. (2007). Entidades de planificación y gestión turística a escala local. El caso de las ciudades patrimonio de la humanidad de España. Cuadernos de Turismo, 20, 79-102.
Glass, R. (1964). Aspects of change. Londres, Reino Unido: University College. Centre for Urban Studies.

González, M. J. (2006). La sostenibilidad de los centros históricos en los albores del siglo XXI. Anales de Geografía de la Universidad Complutense, 26, 49-63.

González-Varas, I. (2006). Conservación de bienes culturales: Teoría, historia, principios y normas. Madrid, España: Cátedra.

González-Varas, I. (2016) La ciudad y su paisaje histórico: tres etapas, tres planteamientos, tres cuestiones críticas. En González-Varas, I. (Ed.) Ciudad, Paisaje y Territorio. Conceptos, métodos y experiencias (pp. 21-62). Madrid: Munilla-Lería.

Gomá, R. (2018). La metrópolis entre la gentrificación y el derecho a la ciudad. Papers: Regió Metropolitana de Barcelona: Territori, estratègies, planejament, 60, 185-187.

Hall, P. (1969). Salvaging our historic towns. New Society, 349, 872-74.

Heidegger, M. (2015). Construir, Habitar, Pensar. Barcelona: La Oficina.

Hernández, A. (2016). De la botiga a la boutique: gentrificación comercial en el Casco Antiguo de Barcelona. URBS Revista de Estudios Urbanos y Ciencias Sociales, 6(1), 79-99.

Hernández, C. (2018). Turismo ¿truco o trato? Políticas públicas y urbanas para el turismo de masas. Madrid, España: Catarata.

Jenks, M., Burton, E. y Williams, K. (Eds.) (1996). The compact city. A Sustainable Urban Form? Londres, Reino Unido: Son.

Kitchin, R. y Tate, N. J. (2000). Conducting research into human geography, theory, methodology \& practice. Harlow, Reino Unido: Prentice Hall.

Koolhaas, R. (1994). La ciudad genérica. Barcelona, España: Gustavo Gili.

Lefevre, H. (2017). El derecho a la ciudad. Madrid, España: Capitán Swing.

Marín, P., Guevara, A. y Navarro-Jurado, E. (2017). Renovación urbana y masificación turística en la ciudad antigua: pérdida de población y conflictos sociales. Ciudad y Territorio. Estudios Territoriales, 193, 454-468. 
Manzano, N. (2018). "Vivir la calle". Análisis y propuestas para el espacio público del casco histórico. En F. Manzano (Ed.), Casco histórico de Toledo. Construir la convivencia (pp. 151-184). Toledo: Toletum Revolutum.

Martínez, E. (2001). Centros históricos en perspectiva. Observaciones sociológicas al análisis y la planificación territorial. Revista Catalana de Sociología, 14, 87-103.

Mega, V. (1996). Our city, our future: towards sustainable development in European cities. Environment and Urbanization, 8(1), 113-154.

Monroy, J. (2015). Últimos retazos del comercio tradicional. La Tribuna de Toledo. Recuperado de https://www.latribunadetoledo.es/noticia/ z2b991e78-0ae1-e3ca-c961b2cd7b4e1d62/ 201509/ultimos-retazos-del-comercio-tradicional

Mumford, E. (2007). El discurso del CIAM sobre el urbanismo 1928-1960. Bitácora Urbano-Territorial, 11(1), 96-115.

Nieto, A. (2012). Espacios públicos recientemente remodelados en el casco antiguo de Madrid (20062011). La Plaza de las Cortes y la Plaza del Callao. Uned. Espacio, Tiempo y Forma. Serie VI, Nueva época. Geografía, 3, 67-75.

Ordeig, J. M. (2004). Diseño urbano y pensamiento contemporáneo. Barcelona, España: Monsa.

Ordoñez, A. (2017). Sentido y significado del casco antiguo contemporáneo. El uso residencial como función a conservar. $Q R U, 8,130-151$.

Pillet, F. (2008). El Catastro Inmobiliario Territorial de Urbana y Rústica en España. Scripta Nova. Revista Electrónica de Geografía y Ciencias Sociales, 12 (274).

Pol, F. (1993). La recuperación de los centros históricos en España. En S. Martínez (Coord.), Jornadas de Estudio Recuperación de Centros Históricos (pp. 109-150). Almería, España: Instituto de Estudios Almerienses.

Pol, F. (2015). La cultura y las políticas de rehabilitación y valorización de los centros históricos. Cuadernos de Investigación Urbanística, 100, 83-86.

Pulido, J. I., De la Calle, M. y Velasco, M. (2013). Turismo Cultural. Madrid, España: Síntesis.

Pulido, J. I. y Ruiz, A. (2017). Propuesta para una agenda de investigación de los impactos del turismo en los destinos Patrimonio de la Humanidad. Bo- letín de la Asociación de Geógrafos Españoles, 73, 389-411.

Ramírez, J. M. (1997). Régimen Jurídico de los cascos antiguos declarados bien de interés cultural-conjunto histórico. Revista Jurídica de Navarra, 23, 155-172.

Reher, D. S. y Valero, A. (2005). Fuentes de información demográfica en España (3a ed.). Madrid, España: CSIC.

Ribas, M. (1981). Problemática de la conservación de los centros históricos. Rehabilitación de ciudades. Barcelona, España: Universidad Politécnica de Barcelona.

Rodwell, D. (2010). Historic cities and sustainable urban development. Context, 114, p. 8.

Ruiz-Apilánez, B., Arnáiz, M. y Ureña, J. M. (2015). Beyond liveable streets. En Vaughan, L. (Ed.), Suburban urbanities: Suburbs and the life of the high street (pp. 130-152). Londres: UCL-Press.

Ruiz-Apilánez, B. y Solís, E. (2016). Del observatorio turístico al observatorio urbano. Una reflexión desde la experiencia de Toledo. En GonzálezVaras, I. (Ed.), Ciudad, paisaje y territorio. Conceptos, métodos y experiencias. Madrid, España: Munilla-Lería.

Santamaría, J. (2013). Cascos históricos: análisis y perspectivas desde la Geografía. GeoGraphos, 4(37), 117-139.

Scarnato, A. (2006). Multiple exposures or new cultural values? European historical centres and recent immigration fluxess. En J. Monclús y $\mathrm{M}$. Guàrdia (Eds.), Culture, Urbanism and Planning, Routledge (libro digital en formato Ebook).

Slater, T.R. (1984). Preservation, conservation and planning in historic towns. The Geographical Journal, 150 (3), 322-334.

Smith, N. (2002). New globalism, new urbanism: Gentrification as global urban strategy. En N. Brenner y N. Theodore (Ed.), Spaces of neoliberalism (pp. 80-103). Oxford, Reino Unido: Blackwell.

Solís, E., Ureña, J. M. y Mohíno, I. (2018). Centralidad territorial y especialización funcional como guía para la intervención en municipios con conjunto histórico. El caso de la región urbana madrileña. Revista ACE - Arquitectura, Ciudad y Territorio, 13 (37), 99-132. 
Sorando, D. y Ardura, A. (2016). First we take Manhattan: la destrucción creativa de las ciudades. Madrid, España: Catarata.

Tiesdell, S. y Heath, T. (1996). Revitalizing historic urban quarters. Oxford, Reino Unido: Architectural Press.

Tomé, S. (2007). Los centros históricos de las ciudades españolas. Ería, 72, 75-88.

Troitiño, M. A. (1991). Centro histórico, intervención urbanística y análisis urbano. Anales de Geografía de la Universidad Complutense, 11, 25-48.

Troitiño, M. A. (1992). Cascos antiguos y centros históricos: problemas, políticas y dinámicas urbanas. Madrid, España: Ministerio de Obras Públicas y Transportes.

Troitiño, M. A. (1999). Turismo y recuperación funcional de los centros históricos. En J. García y M. A. Troitiño (Coords.) Vivir las ciudades históricas: recuperación integrada y dinámica funcional (pp. 115-127). Cuenca, España: Universidad de CastiIla-La Mancha.

Troitiño, M. A. (2003a). Renovación urbana: dinámica y cambios funcionales. Perspectivas Urbanas, 2. Recuperado de https://www.raco.cat/index.php/ Perspectivas/article/view/84980.

Troitiño, M. A. (2003b). La protección, recuperación y revitalización funcional de los cascos históricos. Colección Mediterráneo Económico- Arquitectura y Espacio Urbano, 3, 131-160.

Troitiño, M. A. (2012). Turismo, patrimonio y recuperación urbana en ciudades y conjuntos históricos. Patrimonio cultural de España, 6, 147-163.

Troitiño, M. A., Brandis, D., Del Río, I., De La Calle, M., Gutiérrez, J., Lobo, P. y Martín, F. (1998). Toledo: problemática e implicaciones urbanas del turismo. Eria, 47, 299-325.

Troitiño, M. A., Calle, M., García, M. y Troitiño, L. (2007). La situación turística del Grupo de Ciudades Patrimonio de la Humanidad de España. Bases para la puesta en marcha del observatorio turístico. Grupo de Ciudades Patrimonio de la Humanidad de España y Universidad Complutense de Madrid, León.

Troitiño, M. A. y Troitiño, L. (2010). Patrimonio y turismo: una complementariedad necesaria en un contexto de uso responsable del patrimonio y cualificación de la visita. Patrimonio cultural de España, 3, 89-107.

Valenzuela, M. (1988). Cascos históricos y dinámicas territoriales. En AA.VV. Toledo ¿ciudad vida? ¿ciudad muerta? (pp. 537-551). Toledo, España: Colegio Universitario de Toledo.

Valenzuela, M. (2000). La regeneración de los cascos históricos en España. El programa Urban, dinero comunitario para una estrategia global. En B. Bernal (Coord.). Oportunidades de desarrollo sostenible para los conjuntos urbanos históricos (pp. 87123). Burgos, España: Universidad de Burgos.

Van Oers, R. y Pereira, A. R. (2012). Historic cities as model of sustainability. Journal of Cultural Heritage Management and Sustainable Development, 2(1), 4-14.

Vázquez, A. (2000). Informe sobre la situación del casco histórico de Toledo. Añil, 21, 62-65.

Yin, R. K. (2003). Case study research: design and methods ( 3 a ed.). Thousand Oaks, CA, Estados Unidos: Sage.

Zárate, M. A. (2006). Medio siglo de cambios en los centros urbanos españoles. Estudios Geográficos, 67 (260), 283-315.

Zárate, M. A. y Vázquez, A. (1983). El casco histórico de Toledo. ¿Un espacio urbano vivo? Toledo, España: Zocodover.

Zárate, M. A. y Vázquez, A. (1988). Análisis geográfico del casco histórico de Toledo. En Actas Simposio Toledo, ¿Ciudad viva? ¿Ciudad muerta? Colegio Universitario de Toledo. Del 26 al 30 de abril de 1983.

Zárate, M. A. (1991). Toledo, entre la renovación espontánea y la rehabilitación oficial. Boletín Real Sociedad Geográfica, T. CXXIV-CXXV, 195-210.

Zárate, M. A. (2007). Toledo, planeamiento y especulación en ciudades históricas. Anales de Geografía. Universidad Complutense, 27, 2, 151-175.

Zuccaro, M. (2013). The heart of the city. Continuity and complexity of an urban design concept (tesis doctoral). Universidad Técnica de Delft, Países Bajos. Recuperado de https://repository.tudelft. $\mathrm{nl} /$ islandora/object/uuid:6f06d141-e702-462fa507-524762c7aff0?collection=research. 